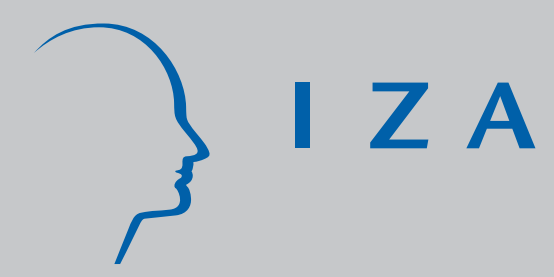

IZA DP No. 1966

Child Labor, Urban Proximity and Household Composition

Marcel Fafchamps

Jackline Wahba

February 2006 


\title{
Child Labor, Urban Proximity and Household Composition
}

\author{
Marcel Fafchamps \\ University of Oxford \\ Jackline Wahba \\ University of Southampton \\ and IZA Bonn
}

\section{Discussion Paper No. 1966 \\ February 2006}

\author{
IZA \\ P.O. Box 7240 \\ 53072 Bonn \\ Germany \\ Phone: +49-228-3894-0 \\ Fax: +49-228-3894-180 \\ Email: iza@iza.org
}

\begin{abstract}
Any opinions expressed here are those of the author(s) and not those of the institute. Research disseminated by IZA may include views on policy, but the institute itself takes no institutional policy positions.

The Institute for the Study of Labor (IZA) in Bonn is a local and virtual international research center and a place of communication between science, politics and business. IZA is an independent nonprofit company supported by Deutsche Post World Net. The center is associated with the University of Bonn and offers a stimulating research environment through its research networks, research support, and visitors and doctoral programs. IZA engages in (i) original and internationally competitive research in all fields of labor economics, (ii) development of policy concepts, and (iii) dissemination of research results and concepts to the interested public.
\end{abstract}

IZA Discussion Papers often represent preliminary work and are circulated to encourage discussion. Citation of such a paper should account for its provisional character. A revised version may be available directly from the author. 
IZA Discussion Paper No. 1966

February 2006

\section{ABSTRACT}

\section{Child Labor, Urban Proximity and Household Composition ${ }^{*}$}

Using detailed survey data from Nepal, this paper examines the determinants of child labor with a special emphasis on urban proximity. We find that children residing in or near urban centers attend school more and work less in total but are more likely to be involved in wage work or in a small business. The larger the urban center, the stronger the effect is. Urban proximity is found to reduce the workload of children and improve school attendance up to 3 hours of travel time from the city. In areas of commercialized agriculture located 3 to 7 hours from the city, children do more farm work. Urban proximity effects are accounted for by a combination of local labor supply and demand conditions, most notably the local importance of agriculture, the education level of the parents, and the local wage rate. Child servants, which represent a small proportion of all children, work much harder than other children and appear particularly at risk.

JEL Classification: J10, J22, J24, J40, N35

Keywords: child labour, Nepal, child schooling, urban proximity

Corresponding author:

Jackline Wahba

Economics Division

University of Southampton

Southampton, SO17 1BJ

United Kingdom

Email: j.wahba@soton.ac.uk

\footnotetext{
${ }^{*}$ We thank for their excellent comments Tim Besley, TN Srinivasan and participants to the conference held on September 24 in Harvard to honor Pranab Bardhan for his contribution to the Journal of Development Economics and the larger field. We are grateful to Forhad Shilpi for her help with the data and to the World Bank for making the data available to us.
} 


\section{Introduction}

Recent years have seen growing concerns regarding the welfare of children in poor countries (e.g. Grootaert \& Kanbur 1995, ILO 2002, Basu \& Tzannatos 2003). Lack of education and child labor have received particular attention as they potentially have dramatic long-term effect on human capital accumulation and hence on development. Furthermore, child labor is often portrayed in the popular press as a growing problem fueled by international trade (Cigno, Rosati \& Guarcello 2002).

The evidence suggests that many children in poor countries do work (e.g. ILO 2002, Ersado 2002, Grootaert \& Kanbur 1995, Basu 1999). In the overwhelming majority of cases, the work performed by children takes place within the household - usually in household chores and on the family farm (Basu \& Ray 2002). Wage work and work in small enterprises remain the exception (ILO 2002). Child labor is considered primarily a rural phenomenon in Africa where children are engaged in farming. In contrast, it is regarded as an urban phenomenon as well in Asia and Latin America where children often also work in small-scale industrial enterprises or in small trade and service businesses. Most child labour studies have focused on rural areas - see Basu (1999) for a survey. A few studies have examined child labour participation at a national level and distinguished between urban and rural areas (e.g. Ersado 2002, Wahba 2005). But those studies do not focus on how urban proximity affects child labour incidence or intensity.

Little is known on whether markets favor an increase or decrease in child labor. In this respect, theory is not a useful guide because it does not make sharp predictions one way or another: depending on substitution elasticities between adult and child labor in production and consumption, the effect of marketization on child labor can go either way (e.g. Edmonds \& Pavcnik 2004, Wahba 2005). Economic theory is also ambiguous regarding the impact of trade policy and globalization on child labour. See for example, Jafarey \& Lahiri (2002). Based on 
the scant available evidence, it does not appear that globalization increases the incidence of child labour (Cigno, Rosati \& Guarcello 2002). Edmonds \& Pavcnik (2004), for instance, study the relationship between trade liberalization (measured as the change in the relative price of an exported commodity) and child labor using household level data from Vietnam. They find that higher rice prices are associated with declines in child labor, suggesting that in this case greater market integration is associated with less child labor, not more.

The purpose of this paper is to throw some indirect light on this important policy question using detailed survey data from Nepal. Unlike Edmonds \& Pavcnik (2004) who use price variation to capture differences in levels of market integration, we rely on cross-section differences in proximity to cities. Jacoby (2000), Fafchamps \& Shilpi (2003) and Fafchamps \& Shilpi (2005) have indeed shown that, in the studied country, proximity to cities is strongly related to market orientation and increased specialization. A cross-section approach has the drawback that it cannot control for unobserved heterogeneity across locations. But it offers the advantage of comparing households at the same point in time and thus in similar macroeconomic conditions, something that cannot be done in studies of child labor based on national time series data.

Our results show that children living in or around cities work more for the market in the form of wage work or small business employment. The increased intensity of market exchange associated with cities thus appears to be empirically correlated with an increased involvement of children in market-related forms of work. At the same time, work by children on the family farm and on household chores falls dramatically with proximity to urban centers. When we combine all three forms of labor, we see that children living in or around cities work in total much less than their rural counterparts. We also find that school attendance increases dramatically with proximity to cities. Taken together, these results suggest that, on average, urban proximity is associated with an improvement in child welfare - at least as far as total child labor and 
education are concerned.

The above findings only holds for the average child, however. We remain concerned that children working for the market may be engaged in dangerous activities. The data show that more than three quarters of child wage employment $(77 \%)$ is in agriculture, a sector where children may have to work long hours in harsh weather and use harmful pesticides and fertilizers. Another $8 \%$ work in domestic services, a sector where abuses of various kind are easy to dissimulate. In the studied country, child wage employment in sectors other than farming and domestic services remains small ( $2 \%$ in construction, $4 \%$ in manufacturing, and $10 \%$ in services).

A few authors have studied child labour in Nepal. Basu \& Ray (2002) have examined the effect of a balanced power structure within the household between the husband and wife on child labour using data from Nepal. Ersado (2002) has focused on the impact of poverty on child labour in rural versus urban areas in three countries: Nepal, Peru, and Zimbabwe. Edmonds (2004) has focused on the sibling differences in child labor in Nepal. He argues that sibling differences reflect comparative advantage in household production. Using the Nepal NLFS survey data, he finds that older girls work more than boys within the same household, because older girls spend more time in domestic work. He also shows that the extra work required of older girls increases in the number of younger siblings (especially younger boys) and the spacing between siblings. Given that the focus of his study is on sibling differences, Edmonds (2004) studies only 6-15 year old children of head with siblings. In contrast, we examine all children in the household who are 5-15 years old.

The paper is organized as follows. In Section 2 we present the conceptual framework underlying our empirical analysis. The data are introduced in Section 3, together with a brief description of the survey area. Econometric results are presented in Section 4. Conclusions appear at the end. 


\section{Conceptual framework}

The incidence of child labor and the form that it takes are driven by supply and demand factors. Supply factors are affected in part by attitudes towards child work. These attitudes are likely to be shaped by public opinion - which may vary with isolation. Supply also depends on decision taken within households. Indeed, most minors are in the custody of their parents or guardian who have the authority to decide whether the child works. Parents' desire to put their children to school may lead them to keep children out of the labor force. The opposite may also arise, as when poor parents partly finance their children's schooling with child work - either directly through child wages, or indirectly by substituting children for adults in house chores or household production. Parents may also choose to sacrifice some children in order to send others to school. Edmonds (2004), for instance, provides some evidence that firstborns are more likely to work, probably to enable their parents to educate younger siblings. For these reasons, household composition is likely to affect the supply of child labor.

Demand factors originate primarily from outside the household. As Fafchamps \& Shilpi (2003) and Fafchamps \& Shilpi (2005) have shown, urban proximity shapes economic activity in many important ways. They find that, in Nepal, households living up to three hours of travel time from cities are more likely to engage in non-farm work than in agriculture. They are also more likely to work for a wage and to rely on the market for a number of goods and services that, in rural areas, are normally self-provided (e.g., food, water, fuel). These changes in the activity mix reflect urban and regional economic processes that have been discussed in great detail elsewhere and need not be revisited here (e.g. Henderson 1988, Fujita, Krugman \& Venables 1999).

Some demand factors originate from within the household itself. This is because most households in poor countries are self-employed. The activities in which a household engages shape 
the demand for child work within the household. Rather than work outside the household for a wage, children may be called to assist in the family farm or business, or to help with household chores. So doing, they free adults to engage in more market-oriented activities. Of course, the health and safety of children is not equally at risk in all these activities. For most parents, involving children in household work is probably seen as an essential part of a good education. But ignoring home production and household chores from an assessment of child labor would result in a distorted image of children's involvement in productive activities.

To guide our econometric analysis, we develop a simple household model in the spirit of Becker (1965), Gronau (1977), and Fafchamps \& Quisumbing (2003). The purpose of the model is to help identify supply and demand forces at work within the household. Since the focus of the model is on the household, we take local market forces as given and we think of them as setting wages and as shaping the range of productive activities in which the household can engage. In the econometric work, these forces external to the household are captured explicitly using variables such as urban proximity, local wages, and other measures of local economic activity.

Consider a household decision model in which altruistic parents make decisions regarding work by their children. For now, we ignore education; it is introduced later. Formally, let the household decision process be represented as the maximization of a welfare function made of weighted individual utilities $U^{i}\left(Y, l_{i}\right)$ where $Y$ denotes household consumption and $l_{i}$ individual leisure. Index 0 denotes the parents and indices 1 and above denote the children. The number of children $N$ is taken as predetermined. ${ }^{1}$ The household is engaged in $K$ activities, each with its own production function and fixed factors $A_{j}{ }^{2}$ Household chores are counted as part of these

\footnotetext{
${ }^{1}$ It is conceivable that parents' decisions regarding the number of children they choose to have be partly determined by their labor needs (e.g. Rosenzweig \& Evenson 1977, Wolpin 1984, Nugent 1985, Rosenzweig \& Schultz 1987, Becker, Murphy \& Tamura 1990). We do not reject this possibility but, in the analysis presented here, we focus on child labor conditional on household composition. Our analysis can thus be construed as focusing on short-term time allocation decisions.

${ }^{2}$ Fixed factors include parental skills, land, equipment, capital, etc.
} 
activities, in which case the imputed value of the services generated by housework is added to consumption. Household members can also hire out their labor force for a wage $w_{i}$. Presumably, $w_{0}>w_{i}$ for $i>0$ in most cases. If the household cannot hire in labor, we have: ${ }^{3}$

$$
\begin{aligned}
\max _{L_{i j} \geq 0, H_{i} \geq 0} \sum_{i=0}^{N} \omega_{i} U^{i}\left(Y, l_{i}\right) \text { subject to } \\
Y=\sum_{j=1}^{K} Q^{j}\left(\bar{A}_{j}, L_{j}\right)+\sum_{i=0}^{N} w_{i} H_{i} \\
L_{j}=\sum_{i=0}^{N} L_{i j} \gamma_{i j} \text { for all } j \\
T_{i}=\sum_{j=1}^{K} L_{i j}+H_{i}+l_{i} \text { for all } i
\end{aligned}
$$

where $\omega_{i}$ denote welfare weights and $\gamma_{i j}$ denotes the productivity of individual $i$ in activity $j$. Equation (2.1) is the usual budget constraint. Equation (2.2) defines effective labor to activity $j .{ }^{4}$ Presumably children are less productive than parents, so that $\gamma_{0 j}>\gamma_{i j}$ for $i>0$ in most cases. We set $\gamma_{0 j}=1$ for all $j$, so that labor is expressed in adult equivalent units. Equation (2.3) is the time constraint. Welfare weights are normalized so that $\omega_{0}=1$. If parents care more for their children than for themselves, $\omega_{i}>1$ and vice versa.

The resulting labor decisions depend on household fixed factors $\bar{A}_{j}$, wages $w_{i}$, productivity coefficients $\gamma_{i j}$, welfare weights $\omega_{i}$, and number of children $N$. We immediately note that leisure consumption $l_{i}$ increases with altruism $\omega_{i}$ : the more altruistic parents feel towards children, the less children work. It is reasonable to assume that for a young enough child, $\gamma_{i j}=w_{i}=0$ and that $\gamma_{i j}$ and $w_{i}$ rise with child age. Consequently, we expect older children to work more than young ones.

\footnotetext{
${ }^{3}$ If the household can freely hire in labor, we have full separability between production decisions and household preferences. The separable case is discussed below when $H_{i}>0$. We also discuss the non separable case when $H_{i}=0$. Separability has been rejected in most empirical applications.

${ }^{4}$ For simplicity, we assume here that the household cannot hire in labor. This assumption is
} 
In general, we expect labor to be allocated to activities where returns to labor are highest. As long as $H_{i}>0,{ }^{5}$ the model behaves like a separable household model. In this case, a simple arbitrage argument predicts $L_{i j}$ to increase with $\bar{A}_{j}$ and $\gamma_{i j}$ and $H_{i}$ to increase with $w_{i}$. These adjustments are accomplished simply by shifting labor between self-production and wage work. Endowments, labor productivity, and wages thus shape what the household does. A household with more land is predicted to devote more labor to agricultural production, much of which will probably come from the household. Higher wages in contrast will divert household labor from farming to wage work. The model also predicts that more productive household members, for instance because of better human capital, will be affected to tasks in which their human capital is most useful (e.g. Fafchamps \& Quisumbing 1999, Yang 1997). These predictions apply to parents as well as children.

Suppose that, because of transactions costs or imperfect markets, $H_{i}$ is constrained to remain positive: the household cannot hire labor for self-production. When $H_{i}=0$, the model then behaves like a non-separable household model (e.g. de Janvry, Fafchamps \& Sadoulet 1991, Key, Sadoulet \& de Janvry 2000). In this case, endowment and productivity effects may be mitigated or even reversed by income effects operating in the opposite direction, or by changes in household shadow prices. Total labor supply depends on price as well as income effects. Provided leisure is a normal good, leisure consumption for all household members increases as $Y$ rises. An increase in $\bar{A}_{j}, w_{i}$, or $\gamma_{i j}$ may therefore generate an income effect so strong that $H_{i}$ falls to zero and the resulting rise in the household shadow wage reduces $L_{i j}$ in all activities, even those where returns to labor rise. Because of this, it is difficult to sign a priori the effect that $\bar{A}_{j}, w_{i}$, or $\gamma_{i j}$ may have on labor - except to say that if the income elasticity of leisure is small, the labor returns effect is likely to dominate and the net effect should be positive. The same prediction

\footnotetext{
${ }^{5}$ Or if $H_{i}$ can become negative.
} 
obtains if the model is separable.

It is reasonable to expect children to be more productive in household activities than in wage work, i.e., to assume that $\gamma_{i j} / \gamma_{o j}>w_{i} / w_{0}$. The reason is that children probably work best under the supervision of their parents. The nominal wage received by children may also overestimate returns to parents if parents fear children to be mistreated or abused by employers. For these reasons, we expect children to work mostly in $K$ self-production activities with their parents. The immediate corollary is that, other things being equal, children in farming households are in general expected to spend more time working than children whose parents do not farm. This is because in non-farming households the marginal return to child labor is lower. Of course, as we have already emphasized, these returns effects may be reversed by sufficiently strong income effects, so that children of large farmers may work less than children of poor landless households even though the returns to child labor are lower for the landless. These income effects are at the heart of the argument of Basu \& Van (1998). It is also reasonable to assume that the gap between $\gamma_{i j} / \gamma_{o j}$ and $w_{i} / w_{0}$ falls as the child gets older, i.e., that $w_{i}$ increases faster with age than $\gamma_{i j}$. Consequently, we expect older children to be more likely to engage in wage work than small children.

The above model can be expanded to allow for education and learning-by-doing. Suppose that the long-term income potential of a child depends on human capital $Z$ which, for the sake of this model, we represent as a vector of skills $Z=\left\{S^{j}\right\}$. Without loss of generality, schooling is represented by $S_{i}^{0}$. Other skills are activity-specific and are acquired through learning-by-doing, i.e., $S_{i}^{j}=S\left(L_{i j}\right)$. The future utility of child $i$ is written $V_{i}\left(S_{i}^{0}, \ldots S_{i}^{K}\right)$ with $\partial V_{i} / \partial S_{i}^{j} \geq 0$ for all 
$j .6$ The decision problem faced by parents now is:

$$
\begin{aligned}
& \max _{L_{i j} \geq 0, H_{i} \geq 0} U^{0}\left(Y, l_{0}\right)+\sum_{i=1}^{N} \omega_{i}\left(U^{i}\left(Y, l_{i}\right)+V_{i}\left(S_{i}^{0}, S\left(L_{i 1}\right), \ldots, S\left(L_{i K}\right)\right)\right. \text { subject to } \\
Y= & \sum_{j=1}^{K} Q^{j}\left(\bar{A}_{j}, L_{j}\right)+\sum_{i=0}^{N} w_{i} H_{i} \\
L_{j}= & \sum_{i=0}^{N} L_{i j} \gamma_{i j} \text { for all } j \\
T_{i}= & S_{i}^{0}+\sum_{j=1}^{K} L_{i j}+H_{i}+l_{i} \text { for all } i
\end{aligned}
$$

The main difference with the earlier model is that an increase in $\omega_{i}$ need not result in an increase in child leisure. This is because if $\gamma_{i j}$ is very small (or even negative), parents may nevertheless decide to involve the child in activity $j$ because doing so generates skills that will be useful to the child later in life. An increase in $\omega_{i}$ nevertheless has an unambiguous effect on schooling, which is predicted to rise with altruism.

Turning to urban proximity, we know from other work in the studied country (e.g. Fafchamps \& Shilpi 2003, Fafchamps \& Shilpi 2005) that it is associated with more emphasis on non-farm activities and wage work, and less emphasis on farming. Agriculture tends to be more market oriented up to three hours travel time from large urban centers, focusing on fruits and vegetables. Commercial agriculture in grains and cash crops predominates between 3 and 8 hours of travel time. Beyond 8 hours of travel time livestock production takes more importance. Very isolated households revert to self-subsistence, except for occasional labor migration.

Fafchamps \& Shilpi (2005) also document large differences in the composition of household chores for households living near urban centers: they spend less time fetching water and firewood but more time shopping and cleaning the house. The emphasis on wage work in and around

\footnotetext{
${ }^{6}$ Discounting is subsumed in function $V_{i}($.$) .$
} 
urban centers and the presence of large employers with a need for literate workers suggest higher returns to education near cities - together with a better supply of schools (Fafchamps \& Quisumbing 1999). For these reasons, we expect school attendance to be higher in the vicinity of urban centers.

The decreased emphasis on agriculture may reduce child labor provided perverse income effects do not force poor urban households to send their children to work outside the household. At the same time, increased opportunities in wage work and non-farm self-employment around cities may raise child labor. Neighborhood effects may also affect parental decisions. Irrespective of whether the ward is rural or urban, the kind of activities undertaken by other individuals in the wards defines work opportunities outside the farm. For this reason we expect less child labor in market oriented activities if other villagers are predominantly occupied in farming. Which of these effects dominates is an unresolved empirical question and the emphasis of this paper.

\section{The data}

We investigate the above empirical questions using survey data from Nepal in the late 1990's. Home to the Everest, Nepal is located nearly entirely at the foot of the Himalaya mountains. It is largely rural, with $86 \%$ of its 21 million inhabitants living in villages or towns of less than 10,000 people. In the early 1990's, Kathmandu, the capital city and largest urban center, had a population of around half a million people. ${ }^{7}$ At the last publicized census, there were only 34 cities and towns of 10,000 inhabitants or more.

Given the mountainous terrain, communications are difficult within Nepal. People living in the remote Northern part of Nepal must trek for many hours by foot or bullock cart before reaching the nearest road. Nepal thus offers a perfect testing ground to examine the effect of

\footnotetext{
${ }^{7}$ 421,000 inhabitants in 1991. Current estimates put the 2000 Kathmandu population level at around 1 million. A population census was conducted in 2001 but the results are not yet available.
} 
proximity to cities on child labor. The institutional setting and legislation regulating child labor and school attendance in Nepal are discussed in detail in Edmonds (2004) and Government of Nepal (1999). Edmonds \& Sharma (2004) documents labor bonding institutions that survive in the extreme Western part of the country and the effect they have on educational investment..

The data we use come from the Nepal Labor Force Survey (NLFS) of 1998/99. The data were collected by the Central Bureau of Statistics of Nepal (CBS). The questionnaire and survey methodology were designed in collaboration with the International Labor Organization, drawing from survey experience in similar countries (Government of Nepal 1999). The NLFS survey data have already been used by Fafchamps \& Shilpi (2005) to study occupational and sectoral specialization and by Edmonds (2004) to study sibling differences in child labor. ${ }^{8}$

It is important to recognize that because the data used here is based on a household survey, it misses certain categories of children that are particularly at risk, such as street children. We also suspect that children engaged in prostitution or bonded labor are not adequately captured or the nature of their work accurately described, although some may live in surveyed households. The results presented here should be interpreted with this caveat in mind.

Geographical coverage in the NLFS is extensive. The survey covers 14,355 urban and rural households spread among 719 villages or 'wards' distributed over 73 of the 75 districts of the country. ${ }^{9}$ Twenty households were selected at random in each ward and employment-related information was collected on each household member except small children (i.e., below the age of 5). Wards are administratively classified as urban and rural on the basis of their sectoral specialization relative to neighboring wards. Rural wards are those that emphasize agriculture;

\footnotetext{
${ }^{8}$ The reader may wonder about the validity and reliability of the NLFS. The reader will find comfort in the fact that, three years prior to the NLFS, the Central Bureau of Statistics of Nepal conducted a Living Standard Measurement Survey (the Nepalese Living Standard Survey or NLSS). The results from this earlier survey can easily be compared with similar LSMS surveys in other countries. This comparison suggests that the work done by CBS is of high quality. This is also the opinion of the World Bank staff in Katmandu.

${ }^{9}$ Two of the most remote districts of the country were not included in the analysis because of difficulties reaching them. Their population is very small so that the resulting bias in negligible.
} 
urban wards are those that do not. Some urban wards are located in moderately large cities; most belong to small towns and district-level administrative centers. By design, half of the surveyed wards were selected in areas classified as 'urban'; the other half were selected in rural areas. Urban areas are thus overrepresented in the sample, a feature that suits our purpose well.

There are some 74,622 individuals identified in the sample. We focus on those who are aged between 5 and 15 years of age - 19,176 individuals in total. ${ }^{10}$ Each of these individuals was asked to describe how much time he or she worked over the seven days preceding the survey. They were asked to distribute their hours of work into 16 different activities which can be divided into three categories: (1) market work, that is, work done primarily or exclusively for the market; (2) what we call subsistence-related work, which may in part be for the market but is largely for self-consumption; and (3) household chores, which are not for the market. The first category includes wage work and work in a non-farm business operated by the household. The second category includes primarily farming, plus a few residual categories such as handicrafts and house construction, which can potentially be provided for the market or for household consumption. The third category includes various household chores, including fetching fuelwood and water, cooking, visiting the market, cleaning, and caring for children and the elderly. Schooling information comes from a question on whether the child is attending school.

Table 1 summarizes respondents' answers. Roughly three quarters of all children aged 5-15 go to school. As is common in South Asia, school attendance is higher among boys than girls (ILO 2002), Kingdon (2003). A little under half of all surveyed children aged 5 to 15 work in one way or another. Less than $5 \%$ of surveyed children perform what we have called market work. One fourth are involved in subsistence work, primarily assisting on their parents' farm, and a third of surveyed children participate in household chores. As could be expected, participation in

\footnotetext{
${ }^{10}$ We eliminated15 households in which the head is a child. Such households do not fit the conceptual framework developed here.
} 
housework is much higher among girls than boys. Participation in all work categories increases with age, together with the number of hours worked in all categories. The increase is strongest in market work because the number of small children involved in market-related work is very small. Finally we note that for those children involved in market work, the average number of hours worked per week is quite high - close to full time work. Corresponding numbers for subsistence and household work are much lower.

We complement these NLFS data with information about urban population in Nepal using the 1991 population census. For our purpose, a town is defined as a settlement of more than 10,000 inhabitants. There were 34 such towns in 1991. We first compute the distance between each of the 719 surveyed ward and each of these towns. Distances are taken along existing roads, except when roads do not exist, in which case we calculate the shortest arc distance to the nearest road, and then the distance to various cities along the road. ${ }^{11}$ Distances are converted into travel time using available information about trucking and walking speeds along various types of roads in Nepal. ${ }^{12}$ Off the road travel is assumed to take place by foot - a reasonable assumption for Nepal given the nature of the terrain.

Available information on distance to the nearest town is summarized in the first two columns of Table 2. The average distance from surveyed wards to the nearest town is around 3 hours, with large differences across wards. Around 30\% of surveyed wards are located either within

\footnotetext{
${ }^{11}$ This is a very time consuming process that requires a combination of various techniques. e.g., visual inspection of maps, statistical information on road grades, calculation of arc distances, comparisons across various measurements to identify shortest distances, etc. The assistance of Jyotsna Puri (GIS lab, Department of Research of the World Bank) was essential to the success of this operation.

${ }^{12}$ Travel speeds are calculated for various terrains and types of road. Assumed travel times are as follows, in $\mathrm{km} /$ hour:

Terai

Siwalik

Highway Provincial road Secondary road Off road

$60 \quad 35$

$51 \quad 29.75$

9.75

24.5

High mountain

42

21

High Himalayas

30

17.5

$\begin{array}{cc}10 & 5 \\ 8.5 & 4.25 \\ 7 & 3.5 \\ 6 & 3 \\ 5 & 2.5\end{array}$

These figures were obtained through discussion with various transportation experts and South Asia operations staff at the World Bank. Travel on highways and provincial roads is assumed to take place by truck; travel on secondary roads is assumed to be by cart.
} 
towns or very close to towns. A little under half of the surveyed children live more than two hours travel away from a town or city; the median distance is 1 hour and 35 minutes. Compared to nationally representative surveys (Fafchamps \& Shilpi 2003), this sample is slightly more urban in the sense that more sample households live in or near towns than in the country as a whole. However, many sample households live far from towns and cities, a reflection of the mountainous and isolated nature of much of Nepal. A quarter of surveyed children are located more than 4 hours travel time from the nearest town; five percent are more than 10 hours away. The extent of this variation makes it easier to identify the effect of distance from towns on child labor. It is the main reason why Nepal is chosen for this study.

We are interested not only in testing the effect of proximity to cities on child labour, but also in identifying the effect of town size. As Fafchamps \& Shilpi (2003) have shown, town size matters. We construct a measure of urban population residing at various distances $h$ from household $i$, denoted $P_{i}^{h}$. To construct these $P_{i}^{h}$ variables, we combine information on distance to towns with data on population in these towns. The resulting variables give the urban population at various time distances from each ward, up to ten hours of travel time. These variables basically measure the urban population residing in a 'donut' defined by travel distance from the ward. To see how the variables are constructed, suppose that a ward $i$ is 2,5 hours away from the nearest town, which has a population of 30,000 . The next nearest town is 4,5 hours away and has a population of 100,000 . Put differently, there is a town in the donut of 2 to 3 hours travel time and another, larger town in the donut of 4-5 hours travel time. In this case we have, for each household in the ward, $\left\{P_{i}^{1} ; \ldots ; P_{i}^{10}\right\}=\{0 ; 0 ; 30,000 ; 0 ; 100,000 ; 0 ; 0 ; 0 ; 0 ; 0\}$. The right-hand columns of Table 2 summarizes the $P_{i}^{h}$ variables. The average surveyed ward has an urban population of 74,000 inhabitants located within an hour of travel time. The median, however, is zero. As could be expected, urban population in each donut increases with distance since the 
area covered by a donut increases with its radius.

\section{Empirical results}

We now turn to econometric analysis. To keep things focused, we use the division of child work into the three broad categories listed in Table 1. We also consider school attendance as a separate dependent variable. We first examine whether a child is involved in any of four activities - market work, subsistence work, housework, and school attendance - as a function of proximity to urban centers. We then seek to identify the source of urban proximity effects. To this purpose, we introduce various controls thought to be correlated with spatial effects and examine the effect on the significance and magnitude of urban proximity variables. If the controls capture spatial effects, urban proximity variables should no longer be significant.

To the extent that child leisure and education are normal goods, we expect children in richer households to work less and to go more to school. Since incomes are also higher in and around cities, the net effect of urban proximity on child labor and education is a priori ambiguous: higher incomes should lower child labor but higher child wages and employment opportunities may raise it - hence the need for empirical investigation.

Fafchamps \& Shilpi (2003) have shown that, in Nepal, proximity to urban centers is associated with more non-farm work and less emphasis on subsistence agriculture. Fafchamps \& Shilpi (2005) further show that wage labor is more frequent in the vicinity of urban centers. These results suggest that wage work and non-farm employment are more readily available near cities. We therefore expect market oriented work to be relatively more prevalent for all household members, including children.

Fafchamps \& Shilpi (2005) also argue that large hierarchies (e.g., large firms, hospitals, schools, public administration) generate higher returns to education in urban areas because the 
skills imparted by schooling are valuable in monitoring and supervision tasks. Consequently, we also expect the demand for schooling to be higher in and around urban areas. Partly for this reason, the supply of schools is also likely to be higher in towns.

\subsection{Reduced form}

We begin by estimating reduced form logit regressions of child labor on urban proximity. ${ }^{13}$ We investigate the effect of urban proximity on dependent variables that take value 1 if the child is involved in one of the four activities list above - market work, subsistence work, housework, and school attendance - and 0 otherwise. We regress these variables on the urban population variables (in $\log )\left\{P_{i}^{1} ; \ldots ; P_{i}^{10}\right\}$ for up to ten hours of travel time, after which the effect of urban proximity tapers off. ${ }^{14}$ These regressions can be construed as summarizing the combined effect of supply and demand factors on child labor and school attendance. To correct for correlation in residuals between observations coming from the same ward, we report logit estimates using ward-level random effects.

To facilitate interpretation, the coefficients of urban population variables are summarized in Figures 1.1-1.5, together with their 95\% confidence interval. We see that child market work and schooling are more likely in the vicinity of urban population while the opposite is true for subsistence work. To investigate which effect dominates, we reestimate the model combining market and subsistence work. The result, presented in Figure 1.5, shows that proximity to urban population is associated with a strong reduction of combined market and subsistence work. This

\footnotetext{
${ }^{13}$ Very similar results are obtained using tobit regressions on hours worked. Because tobit is sensitive to distributional assumptions, we prefer to present logit results as they are more robust.

${ }^{14}$ We also experimented with urban proximity dummies $\left\{D_{i}^{1}, \ldots, D_{i}^{10}\right\}$ with $D_{i}^{k}=1$ if $P_{i}^{k}>0$, and 0 otherwise. Except for market work for which $\left\{D_{i}^{1}, \ldots, D_{i}^{10}\right\}$ and $\left\{P_{i}^{1} ; \ldots ; P_{i}^{10}\right\}$ yield nearly identical likelihood values, urban proximity dummies perform systematically less well than urban population variables, with large differences in likelihood values (40.969 for subsistence work, 15.512 for combined market and subsistence work, 9.58 for housework, and 28.822 for schooling). Spatial patterns are also sharper with urban population variables. We experimented with both sets of variables simultaneously, but multicollinearity between them makes results highly variable and hard to interpret.
} 
implies that children are less likely to work in either of these two activities when they live in and around large population centers. If they work, however, they are more likely to work in market-related activities, possibly without their parents. These results suggest that supply and demand in and around cities combine to reduce child labor in absolute terms but to increase the share of market work. Figures 1.1- 1.5 furthermore show that the effect of urban population on market and subsistence work by children extends over a large area - up to four hours of travel time. Only after 6 hours of travel time do coefficients become mostly non-significant.

For household chores, the effect of urban proximity is non-linear, with a reduction of child labor around cities relative to isolated rural communities, but a compensating positive effect in cities themselves. This may be because children help parents cope with the many demands on their time. As Fafchamps \& Shilpi (2005) have shown, city life is associated with more emphasis on cleaning and cooking. These home-based, relatively light chores ${ }^{15}$ may encourage parents to enlist children help.

We find a strong positive effect of proximity to urban population on schooling, consistent with the idea that cities offer better access to schools and more opportunities to take advantage of a good education. This effects extends well beyond the towns themselves, reaching areas located up to three hours away. We also find that children residing in areas located 4 to 6 hours away from a large city attend school less. This area corresponds with what Fafchamps \& Shilpi (2003) have identified as the commercial farming zone. It is possible that in this zone the work of children is essential to assist parents in agriculture.

One important conclusion thus emerges from the reduced-form analysis presented so far: urban proximity has a strong effect on child labor. The effect extends well beyond the confines of the town itself, reaching areas located up to 5 hours away. This suggests that cities shape

\footnotetext{
${ }^{15}$ Relative to collecting water and fetching firewood.
} 
child labor in surrounding rural areas, introducing a strong differentiation between rural areas (e.g. Fafchamps \& Shilpi 2003, Fafchamps \& Shilpi 2005). An immediate corollary is that the rural-urban dichotomy often used in theoretical and empirical work is insufficiently precise in characterizing the factors affecting child labor.

\subsection{Controlling for household and child characteristics}

The reduced form results presented in Figures 1.1-1.5 provide no information regarding the possible channels through which urban proximity affects child labor. We also worry about the possibility that our results are biased by extraneous factors that affect child labor and happen to be correlated with urban proximity. For these reasons we reestimate the regressions with additional controls, the mean and standard deviation of which are presented in Table 3 .

We are ultimately interested in identifying the respective effects of local labor demand and supply conditions on child labor. As was discussed in the conceptual section, the supply of child labor is expected to depend on household and child characteristics such as household size, child age, etc. We wish to test whether differences in these characteristics can explain differences in child labor outcome across space. To this effect we add a large number of household and child characteristics thought to influence the supply of child labor and we test whether urban proximity variables remain significant. If the relationship between child labor and urban proximity is entirely due to variation in labor supply - and our additional controls adequately capture this variation - urban proximity variable should no longer be significant. Regression results should also indicate which factors most affect child labor supply.

To control for household composition $N$, we include the size of the household and the number of siblings present in the household as well as the number of other children who are less than 6 years of age. We do not have data on household income but since this variable is endogenous 
to child labor decisions, it would not be of much use. We control for adult labor efficiency $\gamma_{i j}$ via the education of the household head and his spouse. To control for permanent income determinants $\bar{A}_{j}$ we include a dummy that takes value 1 if the main occupation of the household head is agriculture. A similar dummy is included for the spouse of the head. A dummy is also included if the household head does not have a spouse because this would affect the household's workload as well as welfare weights.

Child specific regressors contains the gender and age of each child. ${ }^{16}$ To allow for nonlinear age effects on $\gamma_{i j}$, the age of the child enters the regression in the form of age dummy variables. In Section 2 we have shown that child labor in general falls with $\omega_{i}$, except possibly in activities for which there is learning-by-doing. To control for welfare weight effects, we include two variables hypothesized to be correlated with $\omega_{i}$, the welfare weight of the child: birth order and relatedness to the household head.

We include a dummy if the child is declared as a household servant. Such children represent a very small proportion $(0.6 \%)$ of our sample but we expect them to work much harder than other children. We are also interested in finding out in which kind of activity they are involved.

Relatedness to the household head is included as a series of dummies meant to capture the welfare weight of the child relative to that of the head. ${ }^{17}$ Experimental research by psychologists has indeed shown that altruism is an increasing function of the number of genes that two individuals share - a result known as Hamilton's rule (e.g. Brembs 2001, Allison 1992, Cronk 1991, Dawkins 1989). For this reason, we expect children closer related to the household head to work less.

Birth order effects arise if firstborns are favored by parents or, on the contrary, sacrificed

\footnotetext{
${ }^{16}$ Child education is not included because it is jointly determined with work.

${ }^{17}$ Because they do not fit our conceptual framework, we have dropped 15 observations for which the head of household is a child. There are too few observations to analyze child labor in such households.
} 
to provide for younger siblings, as shown for instance by Edmonds (2004). ${ }^{18}$ We think of birth order as fundamentally a distributional issue among siblings. In the absence of birth order effects, workload and school attendance would be distributed equally among children. By affecting relative welfare weights among children of the same household, birth order can raise the workload (or school attendance) of some children while reducing that of others.

To capture this idea formally, let $R_{i}$ stand for birth order (i.e., firstborn $=1$, second born $=2$, etc) and suppose that welfare weights $\omega_{i}=\omega\left(R_{i}\right)$, with the sign of $\omega_{i}^{\prime}$ a priori unknown and $\sum_{i} \omega\left(R_{i}\right)=1$. An easy functional form for $\omega\left(R_{i}\right)$ is to define relative birth order as $r_{i}=\bar{R}-R_{i}$ where $\bar{R}$ is the average birth order of all children in the household, and to let:

$$
\omega_{i}=\alpha+\beta r_{i}
$$

This normalization ensures that $\sum_{i} \omega\left(R_{i}\right)=\alpha$, i.e., that birth order only affects relative welfare among siblings. Because we suspect that birth order matters differently by gender, we compute it separately for boys and girls. Since our focus is on children sent to work by their parents, we compute relative birth order only for children residing in the household; children who have left the household are ignored. Such approach would not necessarily be justified if we studied, say, inheritance. But in our case it is more appropriate since we focus on what happens within the household.

Regional and seasonal dummies are used to control for geographical and climatic characteristics that affect the demand for agricultural labor and that, because of the difficulty of building cities in mountainous terrain, may be correlated with urban proximity. We include East-West

\footnotetext{
${ }^{18}$ A few studies have examined the effect of birth order on child labor. For example, Emerson \& Souza (2002) study the effects of birth order on child labor and school attendance in Brazil. They find that male last-born children are less likely to work and more likely to go to school than their first- and middle-born siblings, which they argue, is because older children can command higher wages. However, they find that females who are first-borns are less likely to attend school and no more or less likely to work than their middle- or last-born siblings because the oldest female children are kept out of school to assist the mother with housework and childcare.
} 
regional dummies as well as dummies for seasons and terrain (which broadly corresponds to the North-South gradient, Terai being the plain bordering India and Mountain being the high altitude area bordering China). We also include as regressor a dummy variable that equals one if the surveyed ward is administratively classified as urban. Edmonds (2004) has indeed shown that child labor is different in urban areas. By survey design, this occurs for about half (46\%) of the sample.

Regression results are summarized in Table 4. We estimated the model for boys and girls separately but since all qualitative results remain unchanged, results are not presented here to save space. The estimated coefficients of the urban dummy show that children residing in wards classified as urban work much less in subsistence work and somewhat less on house chores, but are more likely to attend school. The effect on market work is not significant.

Once we control for the urban dummy, the coefficients of urban population variables become smaller but many remain significant. This indicates that residing in a ward classified as urban does not fully capture the effect of urban proximity. The combined effect of the urban dummy and the urban population variables continue to indicate that children living in urban areas work much less in total.

The remaining effect of the urban variables can basically be interpreted as the combined effect of market labor demand and school supply effects. These effects appear strong since urban population and the urban dummy retain a large independent influence on child labor after controlling for individual labor supply factors. At the same time, since urban proximity coefficients fall relative to their value in Figures 1.1-1.5, we see that labor supply factors account for part of the effect of urban proximity. Results not shown here indicate that much of the effect of household characteristics is attributable to whether parents are involved in farming. Children in farming households are much less likely to engage in market work and much more 
likely to engage in subsistence work and, to a lesser extent, in housework. The positive effect on subsistence work dominates so that the net effect on combined market and subsistence work is strongly positive.

As predicted by the model, we find that the propensity to work increases monotonically with age in all work categories. For market work, the increase is strongest among children aged 14 and above, suggesting that parents are reluctant to let young children work for a wage or as selfemployed workers. We also find strong gender differences, with boys more likely to participate in market work. In contrast, girls are more likely to participate in subsistence work and much more likely to be engaged in household chores. Birth order is also significant, with firstborn boys more likely to enter market work, and firstborn girls more likely to undertake subsistence work, and all firstborn children more likely to undertake household chores. We also find that firstborn girls are less likely to attend school. This suggests that firstborn children are de facto 'sacrificed' in the sense that they are more likely to work and less likely to receive education than their younger siblings. Edmonds (2004) reports a similar finding. One possible explanation is that as households become wealthier over their life cycle, they can better afford sending their children to school.

Results show that child servants are much more likely to be engaged in market work and less likely to attend school or assist the household in subsistence activities. They are slightly more likely to participate in household chores but the effect is not significant.

In their study of South African orphans, Case, Paxson \& Ableidinger (2003) find that orphans are significantly less likely than non-orphans to be enrolled in school. ${ }^{19}$ We also find that children who are more closely related to the household head are more likely to attend school and less likely to engage in market or house work, as predicted by the model presented in Section

\footnotetext{
${ }^{19}$ Using South African data, Zimmerman (2003) finds that fostered children tend to move from homes that have difficulty enrolling them in school to homes that are more apt to do so.
} 
2. ${ }^{20}$ At the same time, they are no less likely to participate in subsistence activities. These results suggest that participation in subsistence work - primarily farming - may be seen as a beneficial activity by parents, probably because it teaches important skills to children. Market and housework, in contrast, are not seen as beneficial, probably because learning is limited and negative externalities present. For household work, these results are consistent with the work of Fafchamps \& Quisumbing (2003) who provide some evidence of rapid learning of household chores in rural Pakistan. We also tested whether Hamilton's rule applies to child labor by checking whether the ratios between the coefficients of the relatedness dummies correspond to those predicted by Hamilton. Test results - presented at the bottom of Table 4 - reject Hamilton's rule except for subsistence work.

Turning to household variables, we find that household size has a strong negative effect on all forms of child labor and a positive effect on schooling. The effect is particularly strong in housework, which confirms the existence of returns to scale in housework (e.g. Deaton \& Paxson 1998, Fafchamps \& Quisumbing 2003). These effects, however, are mitigated by household composition. In particular, we find some evidence of competition for education among siblings (Garg \& Morduch 1998): school attendance falls with an increase in the number of other children in the household, especially young children. Coupled with the rising child participation in household chores that is observed in households with small children, this suggests that children are called to assist their parents in child care provision by substituting for them in housework and, to a lesser extent, in subsistence and market work. As a result they cannot attend school.

To summarize, child labor in market oriented activities is closely related to household size:

\footnotetext{
${ }^{20}$ Endogenous selection is of course a concern. Some children are adopted or fostered (e.g. Zimmerman 2003, Ainsworth 1996, Akresh 2003), and children less directly related to the household head are observed only in households which care enough to adopt or foster them. Household heads who have chosen to look after a child who is not their own are therefore likely to treat this child better than the average head would treat an average distant relative. This bias tends to reduce the difference between own children and fostered children. If we nevertheless find a difference in treatment, this suggest that true effect of relationship to the head is even stronger.
} 
children in households with more adults and fewer children are much less likely to be involved in market work and much more likely to go to school. This suggests that child labor is associated with high child fertility, a feature consistent with theories emphasizing the trade-off between child quantity and quality (e.g. Becker, Murphy \& Tamura 1990, Nugent 1985).

We also find that the education levels of the household head and spouse have a significant negative effect on all forms of child labor and a strong positive effect on schooling. Better educated parents are thus less likely to let their children work and more likely to send them to school. This effect may reflect a direct education effect - better educated parents value education more - or an indirect income effect - wealthier parents can afford to educate their children and to pull them out of the labor force. We also find that the absence of a spouse to the household head is associated with less market work but also less schooling and more subsistence work. It therefore appears that children raised by a single parent work more on the farm to make up for the absence of a spouse.

\subsection{Controlling for local characteristics}

The regression results presented in Table 4 control - as much as possible - for labor supply shifters. The lingering question is whether we can interpret residual urban proximity effects as due mostly to local labor demand and school supply effects. To verify whether there is ground for such an interpretation, we introduce variables that proxy for local labor market and school supply conditions. If introducing these variables eliminates or at least reduces the magnitude of urban proximity variables, this provides tentative evidence that residual urban proximity effects are associated with local labor demand and school supply conditions. ${ }^{21}$

\footnotetext{
${ }^{21}$ Given the data collected in the survey, we do not have information on a number of relevant urban proximity effects, such as prices. Jacoby (2000) has shown that in Nepal land prices and wages vary systematically with distance from markets and urban centers. We expect the same to hold for the price of manufactures, given that most manufactured products consumed in rural areas originate in cities. All proximity effects that are not controlled for explicitly are captured by the urban proximity variables.
} 
Table 5 presents the ward characteristics used to proxy for labor demand effects. ${ }^{22}$ Using information on wages for all salaried workers collected in the NLFS survey, we calculate average adult wages in each ward. Because wages vary with education and education levels vary systematically with distance from urban centers, we calculate an education-corrected average wage in each ward. The estimation is detailed in Appendix. Using a simple arbitrage argument, we expect child wages and returns to self-employed labor to vary across wards in ways that mimic differences in adult wages.

Jacoby (2000) has shown that Nepalese wage levels vary systematically with distance from the nearest town or market. Since we are already controlling for many labor supply effects through household and child characteristics, variation in the wage rate across wards is used to proxy for differences in local labor demand conditions. The conceptual framework presented in Section 2 argues that the effect of wage on labor supply depends on the relative strength of substitution and income effects. If, as assumed for instance by Basu \& Van (1998), the income effect of adult wages dominates the substitution effect, wards with higher adult wages should have less child labor. We also include the average education level of adults and the proportion of migrant households in the ward as other measures of local labor market conditions. ${ }^{23}$

In a country like Nepal where most people are self-employed, the wage rate presents an incomplete picture of local labor market conditions. Agriculture is the major employer in most studied wards. We expect children living in wards where most households farm to be more likely to farm themselves, either directly on their parents' farm or indirectly as agricultural laborers. We have indeed seen that most wage work by children takes the form of agricultural labor. To capture this effect, we use the proportion of adults in the ward who are engaged in subsistence

\footnotetext{
${ }^{22}$ In all cases, own household is omitted from the calculation of the ward mean to avoid spurious correlation.

${ }^{23}$ The migrant variable is calculated as the proportion of households whose head was born outside the ward and migrated to the ward. This information comes from the Nepalese Living Standard Survey (NLSS) of $1996 / 96$. Because the NLFS and NLSS surveys did not visit the same wards, the migrant variable give an average for the same district. There are 73 districts covered in both surveys.
} 
agriculture. On average, more than half of ward households are in agriculture.

School supply also matters. We expect children located closer to schools to be more likely to attend school and less likely to work. To capture school supply conditions, we include the average travel time to the nearest school, in minutes. This variable is only available at the district level. ${ }^{24}$ It is strongly correlated with urban proximity.

Regression results are presented in Table 6 . We see that the inclusion of local variables reduces the magnitude of urban proximity effects. For example, by comparing tables 4 and 6 we see that the coefficient on the urban dummy variable falls dramatically in magnitude for subsistence work and school attendance, while rising slightly for household chores and remaining non-significant for market work. Many urban population variables also become smaller in magnitude or non-significant. These results suggest that urban proximity variables in part reflect local labor market and school supply conditions. A residual urban proximity effect nevertheless remains significant in all cases, probably because, due to data limitations, we only inadequately control for labor supply and demand and school supply conditions. It is also conceivable that attitudes towards child labor vary systematically with geographical isolation, perhaps because western ideals about child welfare have not reached all parts of the country.

Ward and district variables are also interesting in their own right. Most are significant. We observe a strong negative coefficient of the ward wage level in the market subsistence work regressions. This result is consistent with the idea that the income effect dominates the substitution effect in the household decision process: parents living in wards where salaries are higher are less likely to put children to work in the market or on the farm. This finding is in line with Edmonds \& Pavcnik (2004) who show that an increase in the price of agricultural output is associated with a fall of child labor in Vietnam. The effect of wage level on schooling is, as

\footnotetext{
${ }^{24}$ It also comes from the NLSS survey - see previous footnote.
} 
anticipated, strongly positive.

As expected, we find that children living in wards where most adults are engaged in subsistence agriculture are less likely to undertake market work and more likely to engage in subsistence and housework. This confirms the role of local labor market conditions in shaping child labor patterns. The presence of a larger immigrant population is associated with more child market and house work but also more school attendance. The distance to school variable has no significant effect on school attendance. This result is misleading, however. If urban proximity variables are omitted, the distance to school variable has the anticipated negative sign. The lack of significance is probably due to the way our distance to school variable is constructed, i.e., as an average at the district level. Urban proximity variables are measured at the ward level and probably capture distance to school better than the average distance to school at the district level.

\subsection{Hours worked}

So far we have examined child work and schooling propensity. The survey also collected information on hours worked in the week preceding the survey. This enables us to examine the total amount of child work (market, subsistence, and housework) performed in the week preceding the survey. Tobit regression results are presented in Table 7. For comparison purposes, we also report results with hours of child labor in market, subsistence, and house work. ${ }^{25}$ Regressors are the same as those used in Table 6 .

Results confirm that children living in and around urban centers spend less time working in general. This effect is particularly noticeable with the urban dummy, which is significantly negative throughout. Results also indicate an increase in child labor in a zone identified by

\footnotetext{
${ }^{25}$ We also experimented with censored least absolute deviation (CLAD) regressions. Unfortunately, due to heavy censoring (especially in market work), we were unable to obtain convergence, even at higher quantiles.
} 
Fafchamps \& Shilpi (2003) as the zone of commercial agriculture - namely, from 3 to 7 hours of travel time from urban population. This increase in subsistence work is strong enough to generate an increase in the total workload of children.

Other qualitative results are largely unchanged. Wards where adult wages are higher have less child labor. Having farming parents is again shown to have a strong net positive effect on child labor: being born in an agricultural household is a major determinant of child labor. Hours worked by children increase more or less linearly with age.

We also find evidence that children in larger households work less, a result consistent with the existence of returns to scale in household size (Deaton \& Paxson 1998) and (Fafchamps \& Quisumbing 2003). This effect, however, is reversed in households with many children, especially of a young age, in which case other children tend to work more in market and housework. Other results of interest point to the fact that children raised by single parents work more in subsistencerelated activities. Coupled with our findings that children in household with more adults work less and that those in households with more small children work more, these results indicate that child work serves as substitute for adult labor: when there is a shortage of adult labor, children have to participate more.

\section{Conclusion}

Using a large survey data set from Nepal, we have examined the relationship between child labor and urban proximity. Reduced-form regressions indicate that children born in households residing away from urban centers work more than their urban counterparts. The main reason is that rural children assist their parents on the farm and in house chores. We also find that children living near towns and cities are more likely to attend school, a result consistent with a better supply of schools and with the existence of higher returns to education in non-farm activities and 
hence in urban areas (e.g. Fafchamps \& Quisumbing 1999, Fafchamps \& Shilpi 2005). However, while children living in and around urban centers do much less subsistence and housework, they spend more time in market-related activities such as wage employment and work in nonfarm household enterprises. Though a cause for concern, this pattern affects a relatively small proportion of children.

Urban proximity effects go well beyond the traditional rural-urban distinction. Its effect on child labor and schooling is not fully captured by an urban dummy and extends up to 3 to 5 hours of travel time. Cities shape the type of work children do and their propensity to attend school well beyond the confines of cities themselves. Furthermore, we find some evidence that child agricultural work is higher in areas located 3 to 7 hours of travel time from large urban centers. According to Fafchamps \& Shilpi (2003), this corresponds in Nepal to the zone where commercial agriculture is prevalent and focuses on grains and export crops.

We then examine which factors account for these urban proximity effects. To capture household labor supply effects, we add to the regression a number of household and child characteristics thought to influence child labor decisions. We find that the introduction of household and child characteristics reduces the magnitude of the coefficients of urban proximity variables, without eliminating them altogether. This suggests that only part of the urban proximity effects are due to differences in labor supply.

Of the households characteristics that matter most, results indicate that parental education, which is higher in and around urban centers, has a strong negative association with child labor and a positive association with school attendance. This probably reflects both a preference effect - educated parents care more about education - and an income effect - educated parents have a higher income and child leisure is a normal good. The fact that only the education of the household head matters for market work and that it matters more for schooling than education 
of the spouse militates in favor of an income effect. In contrast, the mother's education has a strong negative effect on child participation in household chores, especially for girls. This is probably the result of a direct effect on parental preferences since, in the region, the financial returns to female education are low (Fafchamps \& Quisumbing 1999).

Child labor is affected by household composition, which also varies systematically with urban proximity. Low birth order children (e.g., those born first) are penalized relative to their younger siblings in terms of all categories of work, even after we control for age dummies. They are also less likely to attend school. Taken together, these results suggest that households with many children tend to enlist the help of older siblings to substitute for parents' work. This interpretation is consistent with models of child fertility in which a trade-off exists between the quantity and quality of children (e.g. Becker, Murphy \& Tamura 1990, Becker 1981). Our results illustrate how this trade-off operates in practice: the welfare and education of older siblings is basically 'sacrificed' to help raise their younger siblings (Edmonds 2004). This effect tends to penalize rural children more because they have more siblings on average.

We find in the sample a small number of child servants (less than $0.5 \%$ ) who appear to work long hours doing market work. These children appear the most vulnerable to abuse. We also find that children related closely to the household head work less in total and are more likely to attend school. But they are no less likely to participate in farm work. This suggests that parents probably find farm work beneficial to their children, possibly because they learn professional skills that will be useful in their future life and that they could not learn otherwise.

We investigate whether local labor market and school supply conditions can account for urban proximity effects. Jacoby (2000) has shown that in Nepal land prices and wage rates vary systematically with proximity to urban centers. We find a strong negative association between the wage rate prevailing in a ward and the extent of child labor in market and subsistence work. 
The net effect on total child labor is negative. These findings are in agreement with theoretical predictions and suggest that the income effect dominates the substitution effect, except for house chores.

Agriculture raises child labor even if the household head is not a farmer. Indeed, we find that, after controlling for the occupation of the head, children living in wards with a large proportion of farmers are more involved in subsistence work and in housework. At the same time, we observe less child work in market activities. One possible interpretation of these findings is that children substitute for parents on the family farm when the latter work as agricultural laborers (Fafchamps \& Shilpi 2003).

Taken together the results presented here suggest that child labor cannot be understood in isolation from other forces that affect parents and their capacity to support themselves and their dependents. In rural areas, the participation of children in the family farm and in household chores is probably essential otherwise parents could not cope with the many demands upon their time. In and near urban centers, the situation is in general more favorable to children, with less work and more education. In towns, there is a marginal increase in market-related work but the effect only affects a relatively small proportion of children who tend to be older and predominantly male.

Of more concern is the situation of a small group of children classified as servants. These children work much longer hours than other children, mostly in market work. They represent a small proportion of all children (less than $0.5 \%$ ) but their plight requires special attention. ${ }^{26}$

\footnotetext{
${ }^{26}$ Of course, we do not claim that child servants are worse off than if they had not been put into service. As Akresh (2003) has shown in his study of child fostering in Burkina Faso, while biological children may be treated better than non-biological children by fostering parents, fostered children often are better off than they would have been by staying with their biological parents. This is because fostered children often come from very poor households. The same is probably true of child servants.
} 


\section{Appendix: estimation of the wage equation}

To correct for possible differences in worker characteristics between wards, we first estimate a standard mincerian earnings function by regressing log wage on worker characteristics and ward dummies:

$$
\log w_{i}=X_{i} \beta+\sum_{k=1}^{N} \gamma_{k} D_{i k}+u_{i} w
$$

where $X_{i}$ is the vector of regressors, $D_{i k}$ is a dummy variable for ward $k$, and $\gamma_{k}$ is the wardspecific coefficient. Given the data at our disposal, $X_{i}$ includes a male dummy, worker age, age

squared, years of education, and seasonal dummies. Some $8 \%$ of all 75,000 individuals covered in the survey were working for a wage, generating 6395 observations with wage data Results are summarized in Table A1. Coefficient $\widehat{\gamma}_{k}$ are an estimate of the ward-specific wage level that controls for differences in the gender, age and education composition of the workforce between wards.

This estimate is then corrected to purge the own household effect from the ward average. The correction proceeds as follows. Consider first taking a straight mean of the log wage in each ward. This is equivalent to estimating a model of the form:

$$
\log w_{i}=\sum_{k=1}^{N} \gamma_{k} D_{i k}+u_{i}
$$

with $\widehat{\gamma}_{k}$ being the ward-specific mean of $\log w_{i}$. Taking out the own household effect from the mean is obtained as:

$$
\widehat{\gamma}_{k}^{c}=\frac{N_{k} \widehat{\gamma}_{k}-\log w_{i}}{N_{k}-1}
$$

where $N_{k}$ be the total number of wage earners in ward $k$. Applying this approach to (5.1) 
requires that we take out not just $\log w_{i}$ but $\log w_{i}-X_{i} \widehat{\beta}$. The correction formula becomes:

$$
\widehat{\gamma}_{k}^{c}=\frac{N_{k} \widehat{\gamma}_{k}-\left(\log w_{i}-X_{i} \widehat{\beta}\right)}{N_{k}-1}
$$

In practice, this can be done more easily by noting that, for each $i \in N_{k}$, we have:

$$
\begin{aligned}
\widehat{\log w}_{i} & =X_{i} \widehat{\beta}+\widehat{\gamma}_{k} \\
X_{i} \widehat{\beta} & =\widehat{\log w}_{i}-\widehat{\gamma}_{k}
\end{aligned}
$$

where $\widehat{\log }_{i}$ is the predicted value of $\log w_{i}$ from equation (5.1). The correction formula can thus be rewritten:

$$
\begin{aligned}
\widehat{\gamma}_{k}^{c} & =\frac{N_{k} \widehat{\gamma}_{k}-\left(\log w_{i}-\widehat{\log w_{i}}+\widehat{\gamma}_{k}\right)}{N_{k}-1} \\
& =\widehat{\gamma}_{k}-\frac{\log w_{i}-\widehat{\log w_{i}}}{N_{k}-1}
\end{aligned}
$$

The corrected value, denoted $\widehat{\gamma}_{k}^{c}$, is the one reported in Table 5 together with its standard deviation.

\section{References}

Ainsworth, Martha. 1996. Economic Aspects of Child Fostering in Cote d'Ivoire. In Research in Population Economics. Vol. 8 Greenwich, Conn. and London: T. Paul Schultz (ed.), JAI Press pp. 25-62.

Akresh, Richard. 2003. "Risk, Network Quality, and Family Structure: Child Fostering Decisions in Burkina Faso." mimeograph.

Allison, Paul. 1992. "The Cultural Evolution of Beneficent Norms." Social Forces 71(2):279-301. 
Basu, Kaushik. 1999. "Child Labor: Cause, Consequence, and Cure." Journal of Economic Literature 37(3):1083-119.

Basu, Kaushik \& Pham Hoang Van. 1998. "The Economics of Child Labor." American Economic Review 88(3):412-27.

Basu, Kaushik \& Ranjan Ray. 2002. The Collective Model of the Household and An Unexpected Implication for Child Labour: Hypothesis and an Empirical Test. Technical report World Bank. Working Paper wps2813.

Basu, Kaushik \& Zafiris Tzannatos. 2003. "The Global Child Labor Problem: What Do We Know and What Can We Do?" World Bank Economic Review 17(2):147-173.

Becker, Gary S. 1965. "A Theory of the Allocation of Time.” Economic Journal 75(299):493-517.

Becker, Gary S. 1981. A Treatise on the Family. Cambridge, Mass.: Harvard U.P.

Becker, Gary S., Kevin M. Murphy \& Robert Tamura. 1990. "Capital, Fertility, and Economic Growth." J. Polit. Econ. 98:S12-S37.

Brembs, B. 2001. Hamilton's Theory. In Encyclopaedia of Genetics. Academic Press.

Case, Anne, Christina Paxson \& Joseph Ableidinger. 2003. "Orphans in Africa." (mimeograph).

Cigno, A., F. C. Rosati \& L. Guarcello. 2002. "Does Globalization Increase Child Labour?" World Development 30:1579-89.

Cronk, Lee. 1991. "Human Behavioral Ecology." Annual Review of Anthropology 20:25-53.

Dawkins, Richard. 1989. The Selfish Gene. Oxford: Oxford University Press.

de Janvry, Alain, Marcel Fafchamps \& Elisabeth Sadoulet. 1991. "Peasant Household Behavior with Missing Markets: Some Paradoxes Explained." Economic Journal 101(409):1400-1417. 
Deaton, Angus \& Christina H. Paxson. 1998. "Economies of Scale, Household Size, and the Demand for Food." Journal of Political Economy 106(5):897-930.

Edmonds, Eric \& Nina Pavcnik. 2004. "The Effect of Trade Liberalization on Child Labor." Journal of International Economics . (forthcoming).

Edmonds, Eric \& S. Sharma. 2004. "Is Investment in Human Capital Influenced by Property Rights? Evidence from Families Vulnerable to Bondage." (mimeograph).

Edmonds, Eric V. 2004. "Understanding Sibling Differences in Child Labor.” (mimeograph).

Emerson, Patrick M. \& A.P. Souza. 2002. "Birth Order, Child Labor and School Attendance in Brazil." (mimeograph).

Ersado, L. 2002. Child Labour and School Decisions in Urban and Rural Areas: Cross Country Evidence. Technical report International Food Policy Research Institute Washington, DC.: . FCND Discussion Paper no. 145.

Fafchamps, Marcel \& Agnes R. Quisumbing. 1999. "Human Capital, Productivity, and Labor Allocation in Rural Pakistan." Journal of Human Resources 34(2):369-406.

Fafchamps, Marcel \& Agnes R. Quisumbing. 2003. "Social Roles, Human Capital, and the Intrahousehold Division of Labor: Evidence from Pakistan." Oxford Economic Papers 55(1):3680.

Fafchamps, Marcel \& Forhad Shilpi. 2003. "The Spatial Division of Labor in Nepal." Journal of Development Studies 39(6):23-66.

Fafchamps, Marcel \& Forhad Shilpi. 2005. "Cities and Specialization: Evidence from South Asia." Economic Journal . (forthcoming). 
Fujita, Masahisa, Paul Krugman \& Anthony J. Venables. 1999. The Spatial Economy: Cities, Regions, and International Trade. Cambridge and London: MIT Press.

Garg, A. \& J. Morduch. 1998. "Sibling Rivalry and the Gender Gap: Evidence from Child Health Outcomes in Ghana." Journal of Population Economics 11:471-493.

Gronau, Reuben. 1977. "Leisure, Home Production, and Work - the Theory of the Allocation of Time Revisited." Journal of Political Economy 85(6):1099-1124.

Government of Nepal. 1999. Report on the Nepal Labour Force Survey 1998/99. Kathmandu, Nepal: Central Bureau of Statistics, National Planning Commission Secretariat, His Majesty's Government of Nepal.

Grootaert, C. \& Ravi Kanbur. 1995. "Child Labour: An Economic Perspective.” International Labour Review 134(2):187-203.

Henderson, J. Vernon. 1988. Urban Development: Theory, Fact, and Illusion. New York: Oxford University Press.

ILO. 2002. Every Child Counts: New Global Estimates on Child Labour. Geneva: International Programme on the Elimination of Child Labour, International Labour Office.

Jacoby, Hanan G. 2000. "Access to Markets and the Benefits of Rural Roads." Economic Journal 110(465):713-37.

Jafarey, Saqib \& Sajal Lahiri. 2002. "Will Trade Sanctions Reduce Child Labour?: The Role of Credit Markets." Journal of Development Economics 68(1):137-56.

Key, Nigel, Elisabeth Sadoulet \& Alan de Janvry. 2000. "Transactions Costs and Agricultural Household Supply Response." American Journal of Agricultural Economics 82(2):245-59. 
Kingdon, Geeta. 2003. Where Has All the Bias Gone? Detecting Gender Bias in the Household Allocation of Educational Expenditure. Oxford: Centre for the Study of African Economies, Oxford University. WPS/2003-13.

Nugent, Jeffrey B. 1985. "The Old-Age Security Motive for Fertility." Population and Development Review 11 (1):75-97.

Posel, Dorritt \& Samuel Bowles. 2004. "Genetic Relatedness Predicts Intra-Household Resource Allocations: Evidence from South African Migrants Remittances.” (mimeograph).

Rosenzweig, Mark R. \& Robert Evenson. 1977. "Fertility, Schooling, and the Economic Contribution of Children in Rural India: An Econometric Analysis." Econometrica 45(5):1065-1078.

Rosenzweig, Mark R. \& T. Paul Schultz. 1987. "Fertility and Investments in Human Capital: Estimates of the Consequences of Imperfect Fertility Control in Malaysia." J. Econometrics $36: 163-184$.

Wahba, Jackline. 2005. "The Influence of Market Wages and Parental History on Child Labor and Schooling in Egypt." Journal of Population Economics . (forthcoming).

Wolpin, Kenneth I. 1984. "An Estimable Dynamic Stochastic Model of Fertility and Child Mortality." J. Polit. Econ. 22, No. 5:852-874.

Yang, Dennis T. 1997. "Education and Off-Farm Work." Economic Development and Cultural Change 45 (3):613-632.

Zimmerman, Frederick J. 2003. "Cinderella Goes to School: The Effects of Child Fostering on School Enrollment in South Africa." Journal of Human Resources 38(3):557-90. 
Table 1: Child work and schooling

A. Schooling

Children attending school

B. Work

\section{Market work}

$\%$ of children doing market work

Hours per week

Hours per week for those who work

Subsistence work

$\%$ of children doing subsistence work

Hours per week

Hours per week for those who work

Household chores

$\%$ of children doing household chores

Hours per week

Hours per week for those who work

All Work

$\%$ of children doing any work

Hours per week

Hours per week for those who work

Number of observations

\section{All Boys}

$77.2 \%$

$$
83.6 \%
$$

$4.3 \%$

1.4

32.9

$4.5 \%$

1.6

35.3

$\begin{array}{rr}28.3 \% & 25.6 \% \\ 6.5 & 5.6 \\ 23.1 & 21.8\end{array}$

$31.2 \%$

7.5

24.1

$32.6 \%$

3.6

11.1
$18.5 \%$
1.4
7.8

$47.6 \%$

6.0

12.5

$46.5 \%$

11.6

24.9

$37.5 \%$

8.6

23.0

19176

9876

$56.1 \%$

14.7

26.2

9300

10861 ged 5-10
$76.4 \%$

Aged 11-15

Work information is based on one week recall questions.

Market work refers to wage employment and business self-employment.

Subsistence work combines farming, livestock, and crafts.

All work combines market work, subsistence work, and household chores. 
Table 2 Distance to nearest town and urban proximity variables

\begin{tabular}{|c|c|c|c|c|}
\hline & \multicolumn{2}{|c|}{ Distance to nearest town } & \multicolumn{2}{|c|}{ Urban population } \\
\hline Travel Time & $\%$ of Wards & $\%$ of Children & Mean & Std. Dev. \\
\hline $0-1$ hour & $29.5 \%$ & $26.2 \%$ & 74804 & 180351 \\
\hline $1-2$ hour & $22.1 \%$ & $21.5 \%$ & 54514 & 130480 \\
\hline $2-3$ hour & $9.7 \%$ & $11.0 \%$ & 97443 & 167273 \\
\hline 3-4 hour & $9.5 \%$ & $9.5 \%$ & 151752 & 223457 \\
\hline 4-5 hour & $5.4 \%$ & $5.6 \%$ & 164544 & 225559 \\
\hline 5-6 hour & $3.2 \%$ & $3.6 \%$ & 214631 & 268668 \\
\hline 6-7 hour & $1.9 \%$ & $2.1 \%$ & 342046 & 320305 \\
\hline 7-8 hour & $3.2 \%$ & $3.3 \%$ & 338362 & 320061 \\
\hline 8-9 hour & $1.1 \%$ & $1.2 \%$ & 288493 & 299774 \\
\hline 9-10 hour & $1.7 \%$ & $1.5 \%$ & 341247 & 309812 \\
\hline mber of obser & 719 & 19176 & & \\
\hline
\end{tabular}

The distance to nearest town columns give the proportion of wards and sample child population who live in various travel time ranges from the nearest town.

Urban population refers to the urban population living in each travel distance range from the surveyed wards, based on the 1991 population census. See text for details. 
Table 3: Descriptive statistics of children aged 5-15

Individual characteristics

Percentage of boys

Average age in years

Relative birth order of boys (including children $<5$ )

Relative birth order of girls (including children $<5$ )

Relationship to the head of household (\%)

Son/daughter

Grandchild

Sister/brother

Niece/Nephew

Other

Servant

Household's characteristics

Number of members in the household

Number of siblings in the household

Number of children less than 6 years in household

Years of education of household head

Years of education of spouse of household head

Percentage of households in which head has no spouse

$\%$ of households in which head works in agriculture

$\%$ of households in which spouse of head works in agriculture

Geographical dummies

Ward classified as 'urban' in sampling frame

Mean Std. dev.

$51.5 \%$

10.0

0.19

0.20

0.36

$3.1 \%$

$11.9 \%$

$1.9 \%$

$1.3 \%$

$1.8 \%$

$0.6 \%$

6.54

2.07

0.95

3.71

1.26

$14.3 \%$

$56.3 \%$

$56.9 \%$

$46.3 \%$

$53.7 \%$

Ward classified as 'rural' in sampling frame

$100.0 \%$

Total

$23.7 \%$

$37.5 \%$

$16.9 \%$

$12.4 \%$

$9.4 \%$

$100.0 \%$

$5.5 \%$

$46.2 \%$

$48.3 \%$

$100.0 \%$

19176

Number of observations
2.52

1.59

1.03

4.57

3.08
Hills (below 4000 meters)

Terai (plain bordering India)

Total 
Table 4: Logit regressions on child work and school attendance (with ward-level random effects)

Urban Proximity

Dummy whether ward classified as urban Urban population within 0-1 hour of travel time Urban population within 1-2 hours of travel time Urban population within 2-3 hours of travel time Urban population within 3-4 hours of travel time Urban population within 4-5 hours of travel time Urban population within 5-6 hours of travel time Urban population within 6-7 hours of travel time Urban population within 7-8 hours of travel time Urban population within 8-9 hours of travel time Urban population within 9-10 hours of travel time

Child characteristics:

Male dummy

Relative birth order among boys

Relative birth order among girls

Dummy $=1$ if son/daughter of head of household

Dummy $=1$ if grandchild of head of household

Dummy $=1$ if sister/brother of head of household

Dummy $=1$ if niece/nephew of head of household

Dummy $=1$ if servant

Age of the child (omitted category is 12)

Dummy $=1$ if child age is 5

Dummy $=1$ if child age is 6

Dummy $=1$ if child age is 7

Dummy $=1$ if child age is 8

Dummy $=1$ if child age is 9

Dummy $=1$ if child age is 10

Dummy $=1$ if child age is 11

Dummy $=1$ if child age is 13

Dummy $=1$ if child age is 14

Dummy $=1$ if child age is 15

Household characteristics:

Number of members in the household

Number of siblings in the household

Number of children less than 6 years in household

Years of education of household head

Years of education of spouse of household head

$\%$ of households in which head has no spouse

$\%$ of households in which head works in agriculture

$\%$ of households in which spouse works in agriculture Geographical dummies:

Dummy $=1$ if in Central region

Dummy $=1$ if in Western region

Dummy $=1$ if in Mid-western region

Dummy $=1$ if in Far-western region

Dummy $=1$ if in Hills

Dummy $=1$ if inTerai

Dummy=1 if survey took place in second season

Dummy $=1$ if survey took place in third season

Intercept

Number of observations

esting relationship to head of household:

Joint significance of relationship dummies

Hamilton's rule

Note: Coefficients that are significant at the $10 \%$ level or better appear in boldface.

Market Work

Coeff t-stat

$\begin{array}{ll}-0.063 & -0.41 \\ 0.860 & 1.67\end{array}$

$0.860 \quad 1.67$

$0.144 \quad 0.24$

$0.860 \quad 1.43$

$0.028 \quad 0.06$

$-0.763-1.38$

$0.649 \quad 1.27$

$0.700 \quad 1.66$

$\mathbf{0 . 7 7 4} \quad 1.76$

$-0.028 \quad-0.04$

0.849

1.68

$\begin{array}{ll}-0.009 & -0.08\end{array}$

0.406

0.104

$-0.505$

$-1.115$

0.129

$-0.115$

5.691

$$
2.99
$$

$-4.979 \quad-4.92$

$-5.020 \quad-4.98$

$\mathbf{- 2 . 7 5 6}-8.07$

$-2.280 \quad-8.43$

$\mathbf{- 1 . 3 3 9}-6.11$

$-0.809 \quad-4.90$

$-0.783$

0.103

0.574

0.935

$-4.10$

0.68

4.13

6.84

$\begin{array}{ll}-\mathbf{0 . 1 7 0} & -5.80\end{array}$

$\mathbf{0 . 0 9 6} 2.28$

0.201

$-0.070$

$-0.031$

$-0.596$

$-0.606$

$-1.022$

0.302

0.025

0.150

$-0.226$

0.145

0.983

0.223

0.296

$-2.141$

chi2(4)

19.8

p-value
0.001
Dependent variable $=1$ if child engaged in:

Subsistence Work House Work

Coeff

Coeff

t-stat

$-3.632$

$-2.900$

$-14.32$

Coeff

t-stat

$-0.346 \quad-3.57$

$1.142 \quad 3.27$

$-0.567 \quad-1.47$

$-1.075$

1.284

$-0.175$

0.090

0.251

0.893
0.626

0.748

0.718

$-0.314$

0.418

$-0.514$

0.095

0.198

0.298

0.150

0.603

0.066

$-1.107$

$-4.337$

$-3.823$

$-2.512$

$-1.646$

$-1.149$

$-0.675$

$-0.229$

0.239

0.592

0.510

$-0.075$

0.044

0.020

$-0.041$

$-0.073$

0.508

0.584

0.799

2.40

1.66

0.118

0.513

0.024

0.282

$-0.489$

$-0.41$

0.27

0.76

0.31

1.74

0.08

0.70

$-1.41$

Attending school

Coeff t-sta

$1.017 \quad 9.98$

$0.925 \quad 2.30$

1.192

$-0.028 \quad-0.06$

$0.401 \quad 1.16$

$-0.242 \quad-0.62$

$\mathbf{- 1 . 0 0 1}-3.36$

$-0.130 \quad-0.45$

$-0.645-1.91$

$-0.238 \quad-0.58$

$-0.760-2.08$

$\begin{array}{lll}-8.47 & -2.048 & -35.62\end{array}$

$\mathbf{0 . 2 8 5} \quad 3.79$

$\mathbf{1 . 0 8 1} \quad 18.27$

$-0.049 \quad-0.61$

$-0.161 \quad-2.36$

$1.926 \quad 9.39$

$2.065 \quad 9.86$

$0.204 \quad 0.85$

$\mathbf{1 . 5 4 2} 5.32$

$-4.457-12.36$

$\begin{array}{lll}-2.04 & 0.102 & 0.34\end{array}$

$-23.22$

$-3.842$

$-3.025$

$-27.52$

$-\mathbf{- 1 . 4 2 6}-13.22$

$-0.794 \quad-8.20$

$\begin{array}{lllll}-23.13 & -2.140 & -22.39 & -0.190 & -1.92\end{array}$

$\begin{array}{lllll}-17.52 & -1.681 & -19.06 & \mathbf{0 . 2 1 6} & 2.19\end{array}$

$\begin{array}{lllll}-11.79 & -1.308 & -14.47 & \mathbf{0 . 2 7 5} & 2.54\end{array}$

$\begin{array}{lllll}-7.96 & -0.664 & -8.43 & \mathbf{0 . 1 9 2} & 2.02\end{array}$

$\begin{array}{lll}-2.36 & -0.344 & -3.92\end{array}$

$\begin{array}{ll}0.192 & 2.29 \\ \mathbf{0 . 2 6 1} & 2.29\end{array}$

$-0.188-1.82$

$-0.632-6.42$

$\mathbf{- 1 . 0 7 7}-10.92$

$0.652 \quad 7.88$

0.674

20.14

$\mathbf{0 . 1 1 5} \quad 8.66$

$-0.274$

0.012

0.508

0.59

$\mathbf{- 0 . 1 5 0}-7.30$

$\mathbf{- 0 . 2 0 4}-6.62$

$\mathbf{0 . 2 0 9} \quad 25.35$

$\mathbf{0 . 0 8 5} \quad 5.16$

$0.041 \quad 0.47$

$\mathbf{0 . 1 0 2} \quad 1.78$

$\begin{array}{ll}-0.155 & -2.29\end{array}$

$-0.556$

-0.556
-0.509

0.945

0.940

0.346

0.039

$-0.039$

$-0.336$

$-0.419$

19176

$-0.387$

$-2.72$

$-3.26$

$-0.564$

0.160

0.999

0.233

$-0.091$

$-0.363$

$-0.045$

0.004

2.860

19176

-3.86
1.06

0.574

$-0.540-3.42$

$-0.316 \quad-1.85$

$\begin{array}{rrr}-0.47 & -0.316 & -1.85 \\ -1.89 & -0.601 & -3.38\end{array}$

$-1.89-0.601 \quad-3.38$

$\begin{array}{lll}-0.44 & -0.058 & -0.56\end{array}$

$0.04-0.085 \quad-0.78$

9.59

$-1.156$

$-3.81$

19176

p-value
0.055
p-value

p-value

chi2(4)

p-value

$\begin{array}{lrrr}11.52 & 0.021 & 225.130 & 0.000\end{array}$

$\begin{array}{rrrrrr}\text { chi2(3) } & \text { p-value } & \text { chi2(3) } & \text { p-value } & \text { chi2(3) } & \text { p-value } \\ 3.64 & 0.303 & 6.81 & 0.078 & 219.56 & 0.000\end{array}$

0.078

0.000 
Table 5. Ward characteristics

Ward variables computed from the Nepal Labor Force Survey

Mean Std. dev.

Average adult wage in logs (see appendix for details)

Percentage of adults working in subsistence agriculture

Average years of education for adults

District averages computed from the Nepal Living Standards Survey

$\%$ of head of household born outside ward of residence

Average travel time to school (in hours)

0.36

Note: to avoid spurious correlaton, all ward variables are calculated by omitting the child's own household. See the appendix for the calculation of the adult wage. 
Table 6: Logit regressions on child work and school attendance (with ward-level random effects)

Ward variables:

Average adult wage in logs

$\%$ of adults working in subsistence agriculture

Average years of education for adults

District variables:

$\%$ of hh heads born outside ward of residence

Average travel time to school (in hours)

Urban Proximity

Dummy whether ward classified as urban

Urban population within 0-1 hour of travel time

Urban population within 1-2 hours of travel time

Urban population within 2-3 hours of travel time

Urban population within 3-4 hours of travel time

Urban population within 4-5 hours of travel time

Urban population within 5-6 hours of travel time

Urban population within 6-7 hours of travel time

Urban population within 7-8 hours of travel time

Urban population within 8-9 hours of travel time

Urban population within 9-10 hours of travel time

Child characteristics:

Male dummy

Relative birth order among boys

Relative birth order among girls

Dummy $=1$ if son/daughter of head of household

Dummy $=1$ if grandchild of head of household

Dummy $=1$ if sister/brother of head of household

Dummy $=1$ if niece/nephew of head of household

Dummy= 1 if servant

Age of the child (omitted category is 12)

Dummy $=1$ if child age is 5

Dummy $=1$ if child age is 6

Dummy $=1$ if child age is 7

Dummy $=1$ if child age is 8

Dummy $=1$ if child age is 9

Dummy $=1$ if child age is 10

Dummy $=1$ if child age is 11

Dummy $=1$ if child age is 13

Dummy $=1$ if child age is 14

Dummy $=1$ if child age is 15

Household characteristics:

Number of members in the household

Number of siblings in the household

Number of children less than 6 years in household

Years of education of household head

Years of education of spouse of household head

$\%$ of households in which head has no spouse

$\%$ of households in which head works in agriculture

$\%$ of households in which spouse works in agriculture

Geographical dummies:

Dummy $=1$ if in Central region

Dummy $=1$ if in Western region

Dummy $=1$ if in Mid-western region

Dummy $=1$ if in Far-western region

Dummy $=1$ if in Hills

Dummy=1 if inTeral

Dummy $=1$ if survey took place in second season

Dummy $=1$ if survey took place in third season

Intercept

Number of observations

Note: Coefficients that are significant at the $10 \%$ level or better appear in boldface.
Dependent variable $=1$ if child engaged in:

Subsistence Work House Work

House Work

$\begin{array}{lllllrrr}-0.698 & -3.41 & -0.232 & -1.30 & 0.203 & 1.43 & \mathbf{0 . 3 9 9} & 3.07\end{array}$

$\begin{array}{llllllll}\mathbf{- 1 . 3 8 9} & -3.77 & \mathbf{2 . 2 2 1} & 6.44 & 0.300 & 1.10 & 0.144 & 0.57\end{array}$

$\begin{array}{llllllll}0.002 & 0.04 & -\mathbf{0 . 2 0 3} & -3.91 & 0.021 & 0.62 & \mathbf{0 . 2 0 1} & 5.49\end{array}$

$\begin{array}{llllllll}\mathbf{1 . 0 4 8} & 2.08 & -0.772 & -1.42 & \mathbf{0 . 5 9 9} & 1.73 & \mathbf{1 . 3 0 7} & 4.19\end{array}$

$\begin{array}{llllllll}0.181 & 0.50 & \mathbf{- 0 . 6 1 4} & -2.75 & 0.066 & 0.28 & 0.277 & 1.26\end{array}$

$\begin{array}{llllllll}-0.283 & -1.51 & -0.626 & -3.14 & -0.428 & -3.25 & 0.354 & 2.95\end{array}$

$\begin{array}{llllllll}0.292 & 0.51 & \mathbf{- 2 . 4 9 1} & -3.82 & \mathbf{1 . 0 2 5} & 2.54 & 0.016 & 0.04\end{array}$

$\begin{array}{llllllll}-0.352 & -0.55 & \mathbf{- 2 . 8 2 5} & -4.31 & \mathbf{- 1 . 1 1 0} & -2.49 & 0.636 & 1.38\end{array}$

$\begin{array}{llllllll}0.319 & 0.56 & -0.200 & -0.22 & -0.364 & -0.83 & -0.309 & -0.68\end{array}$

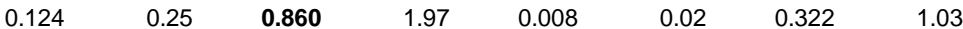

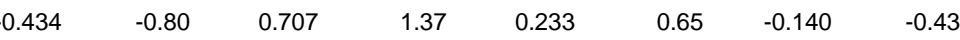

$\begin{array}{llllllll}0.554 & 1.10 & 0.765 & 1.63 & 0.247 & 0.69 & -0.691 & -2.20\end{array}$

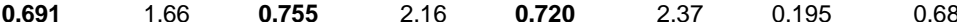

$\begin{array}{llllllll}0.892 & 1.99 & -0.317 & -0.89 & 0.210 & 0.63 & -0.140 & -0.48\end{array}$

$\begin{array}{llllllll}0.435 & 0.66 & -0.466 & -0.93 & 0.299 & 0.68 & -0.081 & -0.21\end{array}$

$\begin{array}{llllllll}0.742 & 1.48 & 0.126 & 0.29 & -0.484 & -1.34 & -0.335 & -0.94\end{array}$

$\begin{array}{llllllll}0.007 & 0.06 & \mathbf{- 0 . 5 1 1} & -8.00 & \mathbf{- 2 . 0 7 7} & -34.42 & \mathbf{1 . 0 6 5} & 17.10\end{array}$

$\begin{array}{llllllll}\mathbf{0 . 4 2 6} & 3.10 & 0.113 & 1.37 & \mathbf{0 . 2 9 9} & 3.77 & -0.060 & -0.71\end{array}$

$\begin{array}{llllllll}0.078 & 0.55 & \mathbf{0 . 2 1 8} & 2.86 & \mathbf{0 . 2 9 9} & 4.44 & \mathbf{- 0 . 1 4 8} & -2.05\end{array}$

$\begin{array}{llllllll}-\mathbf{0 . 5 8 3} & -2.04 & 0.308 & 1.34 & \mathbf{- 0 . 4 5 1} & -2.28 & \mathbf{2 . 0 2 5} & 9.51\end{array}$

$\begin{array}{llllllll}\mathbf{- 1 . 1 4 5} & -3.40 & 0.143 & 0.61 & -0.502 & -2.46 & \mathbf{2 . 1 4 9} & 9.87\end{array}$

$\begin{array}{llllllll}0.102 & 0.29 & \mathbf{0 . 6 6 7} & 2.50 & -\mathbf{0 . 7 6 8} & -3.21 & 0.166 & 0.67\end{array}$

$\begin{array}{llllllll}-0.086 & -0.19 & -0.017 & -0.05 & -0.268 & -0.99 & \mathbf{1 . 4 8 6} & 4.97\end{array}$

$\begin{array}{llllllll}\mathbf{5} .567 & 12.21 & \mathbf{- 1 . 0 3 0} & -1.85 & 0.141 & 0.47 & \mathbf{- 4 . 7 8 9} & -12.80\end{array}$

$\begin{array}{llllllll}\mathbf{- 4 . 9 8 1} & -4.92 & \mathbf{- 4 . 0 8 5} & -21.50 & \mathbf{- 3 . 8 0 6} & -26.14 & \mathbf{- 1 . 3 8 6} & -12.31\end{array}$

$\begin{array}{llllllll}\mathbf{- 5 . 0 1 9} & -4.98 & \mathbf{- 3 . 6 9 4} & -24.64 & \mathbf{- 3 . 0 4 1} & -25.80 & \mathbf{- 0 . 7 1 8} & -7.10\end{array}$

$\begin{array}{llllllll}\mathbf{- 2 . 7 4 5} & -8.04 & \mathbf{- 2 . 3 7 7} & -20.82 & \mathbf{- 2 . 1 4 4} & -21.33 & \mathbf{- 0 . 1 9 3} & -1.86\end{array}$

$\begin{array}{llllllll}-\mathbf{2 . 2 7 8} & -8.42 & \mathbf{- 1 . 5 6 0} & -15.86 & \mathbf{- 1 . 7 1 3} & -18.54 & \mathbf{0 . 2 4 2} & 2.36\end{array}$

$\begin{array}{llllllll}\mathbf{- 1 . 3 1 2} & -5.97 & \mathbf{- 1 . 0 5 9} & -10.29 & \mathbf{- 1 . 2 9 1} & -13.61 & \mathbf{0 . 2 6 5} & 2.33\end{array}$

$\begin{array}{llllllll}-\mathbf{0 . 7 9 4} & -4.80 & -\mathbf{0 . 6 4 8} & -7.29 & -\mathbf{0 . 6 7 3} & -8.20 & \mathbf{0 . 2 0 2} & 2.03\end{array}$

$\begin{array}{llllllll}-0.789 & -4.10 & -0.214 & -2.10 & -0.362 & -3.96 & \mathbf{0 . 3 1 6} & 2.62\end{array}$

$\begin{array}{llllllll}0.076 & 0.49 & \mathbf{0 . 2 4 5} & 2.49 & \mathbf{0 . 3 1 1} & 3.53 & -0.146 & -1.33\end{array}$

$\begin{array}{llllllll}\mathbf{0 . 5 1 9} & 3.67 & \mathbf{0 . 6 4 8} & 6.71 & \mathbf{0 . 6 8 8} & 7.97 & \mathbf{- 0 . 6 1 6} & -5.96\end{array}$

$\begin{array}{llllllll}\mathbf{0 . 9 3 1} & 6.74 & \mathbf{0 . 5 0 4} & 5.12 & \mathbf{0 . 6 9 0} & 7.81 & \mathbf{- 1 . 0 6 0} & -10.25\end{array}$

$\begin{array}{llllllll}\mathbf{- 0 . 1 7 3} & -5.85 & \mathbf{- 0 . 0 7 2} & -4.90 & \mathbf{- 0 . 2 6 9} & -18.93 & \mathbf{0 . 1 1 8} & 8.47\end{array}$

$\begin{array}{llllllll}\mathbf{0 . 1 1 0} & 2.59 & \mathbf{0 . 0 4 4} & 1.93 & 0.000 & 0.02 & \mathbf{- 0 . 1 6 8} & -7.73\end{array}$

$\begin{array}{llllllll}\mathbf{0 . 2 0 3} & 3.16 & -0.012 & -0.34 & \mathbf{0 . 5 0 5} & 15.80 & \mathbf{- 0 . 1 8 1} & -5.63\end{array}$

$\begin{array}{llllllll}\mathbf{0 . 0 7 2} & -5.46 & \mathbf{- 0 . 0 3 7} & -4.84 & \mathbf{- 0 . 0 1 2} & -1.94 & \mathbf{0 . 2 1 1} & 24.46\end{array}$

$\begin{array}{llllllll}-0.028 & -1.52 & -0.062 & -4.00 & -0.032 & -3.37 & \mathbf{0 . 0 7 6} & 4.48\end{array}$

$\begin{array}{llllllll}-0.546 & -3.67 & \mathbf{0 . 4 7 2} & 4.72 & 0.088 & 1.08 & 0.064 & 0.71\end{array}$

$\begin{array}{llllllll}\mathbf{0 . 5 5 3} & -4.77 & \mathbf{0 . 5 4 1} & 8.97 & 0.060 & 1.06 & \mathbf{0 . 1 3 4} & 2.26\end{array}$

$\begin{array}{llllllll}\mathbf{- 0 . 9 5 5} & -7.90 & \mathbf{0 . 7 7 0} & 10.16 & 0.084 & 1.30 & \mathbf{- 0 . 1 3 3} & -1.88\end{array}$

$\begin{array}{llllllll}0.132 & 0.62 & -0.767 & -4.13 & -0.592 & -3.83 & -0.453 & -3.23\end{array}$

$\begin{array}{llllllll}-0.011 & -0.05 & -0.526 & -2.75 & -0.022 & -0.14 & 0.222 & 1.47\end{array}$

$0.217 \quad 0.85-0.420$

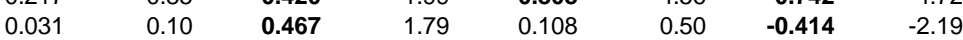

$\begin{array}{llllllll}-0.058 & -0.13 & 0.316 & 1.07 & -0.128 & -0.54 & 0.204 & 0.94\end{array}$

$\begin{array}{lllll}0.40 & -0.414 & -1.62 & -0.841 & -3.58\end{array}$

$\begin{array}{llllllll}0.340 & 2.21 & -0.157 & -1.13 & -0.019 & -0.17 & -0.155 & -1.47\end{array}$

$\begin{array}{llllllll}\mathbf{0 . 4 0 4} & 2.65 & -\mathbf{0 . 3 1 6} & -2.27 & -0.033 & -0.29 & -0.136 & -1.29\end{array}$

$\begin{array}{llllllll}0.624 & 0.81 & -0.352 & -0.49 & \mathbf{2 . 0 8 6} & 4.09 & \mathbf{- 2 . 7 5 9} & -5.79\end{array}$

$\begin{array}{lll}17714 & 17714 & 17714\end{array}$ 
Ward variables:

Average adult wage in logs

$\%$ of adults working in subsistence agriculture

Average years of education for adults

District variables:

$\%$ of hh heads born outside ward of residence

Average travel time to school (in hours)

Urban Proximity

Dummy whether ward classified as urban

Urban population within 0-1 hour of travel time

Urban population within 2-3 hours of travel time

Urban population within 3-4 hours of travel time

Urban population within 4-5 hours of travel time

Urban population within 5-6 hours of travel time

Urban population within 6-7 hours of travel time

Urban population within 7-8 hours of travel time

Urban population within 8-9 hours of travel time

Urban population within 9-10 hours of travel time

Child characteristics:

Male dummy

Relative birth order among boys

Relative birth order among girls

Dummy $=1$ if son/daughter of head of household

Dummy $=1$ if grandchild of head of household

Dummy $=1$ if sister/brother of head of household

Dummy $=1$ if niece/nephew of head of household

Dummy $=1$ if servant

Age of the child (omitted category is 12)

Dummy $=1$ if child age is 5

Dummy $=1$ if child age is 6

Dummy $=1$ if child age is 7

Dummy $=1$ if child age is 8

Dummy $=1$ if child age is 9

Dummy $=1$ if child age is 10

Dummy $=1$ if child age is 11

Dummy $=1$ if child age is 13

Dummy $=1$ if child age is 14

Dummy $=1$ if child age is 15

Household characteristics:

Number of members in the household

Number of siblings in the household

Number of children less than 6 years in household

Years of education of household head

Years of education of spouse of household head

$\%$ of households in which head has no spouse

$\%$ of households in which head works in agriculture

$\%$ of households in which spouse works in agriculture

Geographical dummies:

Dummy $=1$ if in Central region

Dummy $=1$ if in Western region

Dummy $=1$ if in Mid-western region

Dummy $=1$ if in Far-western region

Dummy $=1$ if in Hills

Dummy $=1$ if inTera

Dummy $=1$ if survey took place in second season

Dummy $=1$ if survey took place in third season

Intercept

Number of observations

Number of uncensored observations
Urban population within 1-2 hours of travel time

\begin{tabular}{|c|c|c|c|c|c|c|c|}
\hline \multicolumn{2}{|c|}{ Market Work } & \multicolumn{2}{|c|}{ Subsistence Work } & \multicolumn{2}{|c|}{ House Work } & \multicolumn{2}{|c|}{ All work } \\
\hline Coeff & t-stat & Coeff & t-stat & Coeff & t-stat & Coeff & t-stat \\
\hline-15.662 & -4.61 & -4.682 & -5.86 & 0.531 & 1.23 & -3.586 & -5.50 \\
\hline-32.704 & -5.20 & 20.214 & 11.50 & 1.305 & 1.48 & 5.703 & 4.27 \\
\hline-0.101 & -0.12 & -1.875 & -7.00 & -0.107 & -0.90 & -0.492 & -2.65 \\
\hline 24.235 & 2.92 & -6.911 & -3.41 & 4.763 & 4.42 & 0.358 & 0.22 \\
\hline 4.291 & 0.69 & -5.716 & -4.31 & 0.124 & 0.18 & -2.366 & -2.21 \\
\hline-5.277 & -1.68 & -5.749 & -7.73 & -2.178 & -5.52 & -6.241 & -10.43 \\
\hline 5.313 & 0.55 & -29.380 & -7.52 & 0.726 & 0.52 & -1.664 & -0.77 \\
\hline-9.691 & -0.88 & -24.972 & -7.75 & -8.307 & -5.56 & -20.570 & -8.97 \\
\hline 5.612 & 0.59 & 0.348 & 0.12 & -2.582 & -1.75 & -1.554 & -0.71 \\
\hline 3.240 & 0.40 & 9.898 & 4.73 & -0.388 & -0.34 & 4.593 & 2.75 \\
\hline-7.967 & -0.89 & 9.230 & 4.43 & 0.916 & 0.80 & 5.349 & 3.15 \\
\hline 12.956 & 1.58 & 7.151 & 3.50 & 1.311 & 1.15 & 7.718 & 4.56 \\
\hline 15.252 & 2.20 & 7.952 & 4.62 & 4.417 & 4.71 & 9.662 & 6.89 \\
\hline 18.248 & 2.48 & -3.647 & -1.88 & 0.267 & 0.25 & 0.048 & 0.03 \\
\hline 10.793 & 0.97 & -2.886 & -1.11 & 2.968 & 2.14 & 2.030 & 0.96 \\
\hline 15.290 & 1.87 & 2.839 & 1.31 & -3.143 & -2.79 & -1.583 & -0.93 \\
\hline 0.650 & 0.24 & -5.922 & -8.30 & -13.578 & -35.16 & -13.550 & -24.38 \\
\hline 10.705 & 3.29 & 2.352 & 2.53 & 1.784 & 3.39 & 4.165 & 5.57 \\
\hline 0.341 & 0.10 & 2.654 & 3.17 & 1.961 & 4.76 & 2.972 & 4.52 \\
\hline-23.531 & -3.45 & 0.172 & 0.07 & -8.320 & -7.52 & -13.198 & -7.45 \\
\hline-35.187 & -4.49 & -4.873 & -1.95 & -8.845 & -7.64 & -17.418 & -9.45 \\
\hline-4.392 & -0.53 & 3.314 & 1.17 & -8.456 & -6.07 & -6.828 & -3.16 \\
\hline-9.610 & -0.89 & -5.269 & -1.49 & -7.677 & -4.68 & -13.803 & -5.39 \\
\hline 108.450 & 12.61 & -15.304 & -2.57 & 3.743 & 2.10 & 50.742 & 18.24 \\
\hline-103.251 & -6.19 & -45.337 & -22.95 & -23.949 & -26.51 & -47.828 & -34.58 \\
\hline-100.668 & -6.28 & -40.985 & -25.40 & -18.343 & -24.74 & -40.662 & -35.53 \\
\hline-61.115 & -8.64 & -25.934 & -20.07 & -12.988 & -19.99 & -28.006 & -28.55 \\
\hline-52.058 & -8.91 & -16.947 & -15.08 & -10.938 & -18.12 & -21.715 & -24.28 \\
\hline-31.286 & -6.26 & -11.374 & -9.69 & -8.194 & -13.20 & -15.578 & -16.82 \\
\hline-18.925 & -4.89 & -6.812 & -6.70 & -4.494 & -8.37 & -9.305 & -11.48 \\
\hline-17.364 & -3.88 & -2.854 & -2.49 & -2.415 & -4.06 & -5.141 & -5.68 \\
\hline 2.110 & 0.57 & 2.494 & 2.30 & 1.965 & 3.50 & 2.829 & 3.28 \\
\hline 12.623 & 3.70 & 7.212 & 6.92 & 3.882 & 7.18 & 8.608 & 10.35 \\
\hline 22.908 & 6.79 & 6.425 & 5.99 & 4.967 & 8.99 & 11.344 & 13.35 \\
\hline-4.344 & -6.40 & -0.724 & -4.56 & -1.890 & -21.70 & -2.285 & -17.93 \\
\hline 2.555 & 2.60 & -0.398 & -1.62 & 0.092 & 0.70 & 0.093 & 0.47 \\
\hline 5.611 & 3.76 & 0.468 & 1.26 & 4.001 & 20.15 & 4.204 & 14.16 \\
\hline-1.702 & -5.57 & -0.434 & -5.20 & -0.151 & -3.73 & -0.620 & -9.91 \\
\hline-0.616 & -1.48 & -0.628 & -3.85 & -0.204 & -3.35 & -0.299 & -3.09 \\
\hline-12.064 & -3.50 & 6.327 & 5.83 & 0.306 & 0.61 & 0.484 & 0.62 \\
\hline-12.636 & -4.70 & 6.241 & 9.35 & 0.273 & 0.78 & 2.886 & 5.44 \\
\hline-19.870 & -7.01 & 11.765 & 14.11 & 0.489 & 1.25 & 2.878 & 4.80 \\
\hline 0.482 & 0.14 & -8.781 & -9.79 & -3.134 & -6.42 & -6.567 & -9.11 \\
\hline-1.301 & -0.33 & -7.805 & -8.12 & -1.022 & -1.99 & -5.954 & -7.66 \\
\hline 3.211 & 0.79 & 4.190 & 4.39 & 2.411 & 4.74 & 4.892 & 6.29 \\
\hline 0.836 & 0.16 & 3.128 & 2.80 & -0.950 & -1.54 & 1.043 & 1.12 \\
\hline 1.793 & 0.23 & 2.253 & 1.74 & -0.827 & -1.13 & 0.586 & 0.53 \\
\hline 6.180 & 0.78 & 1.019 & 0.69 & -2.775 & -3.46 & -2.052 & -1.68 \\
\hline 5.928 & 2.31 & -2.717 & -4.13 & -1.117 & -3.31 & -2.693 & -5.24 \\
\hline 8.586 & 3.39 & -4.661 & -7.04 & -1.220 & -3.61 & -3.227 & -6.27 \\
\hline 14.145 & 0.99 & 5.636 & 1.52 & 22.737 & 12.11 & 53.847 & 18.60 \\
\hline 17714 & & 17714 & & 17714 & & 17714 & \\
\hline 799 & & 4754 & & 5664 & & 8060 & \\
\hline
\end{tabular}

Note: Coefficients that are significant at the $10 \%$ level or better appear in boldface. 
Table A1: Mincerian Earnings Function

The dependent variable is the log of hourly wage for adults.

Male dummy
Age
Age squared
Years of education
Ward dummies
Intercept

Number of observations

Adjusted R-squared
Coeff t-stat

$0.203 \quad 12.16$

$0.037 \quad 10.82$

$0.000 \quad-8.43$

$0.055 \quad 35.61$

included but not shown

$1.214 \quad 4.56$

6526

0.52 


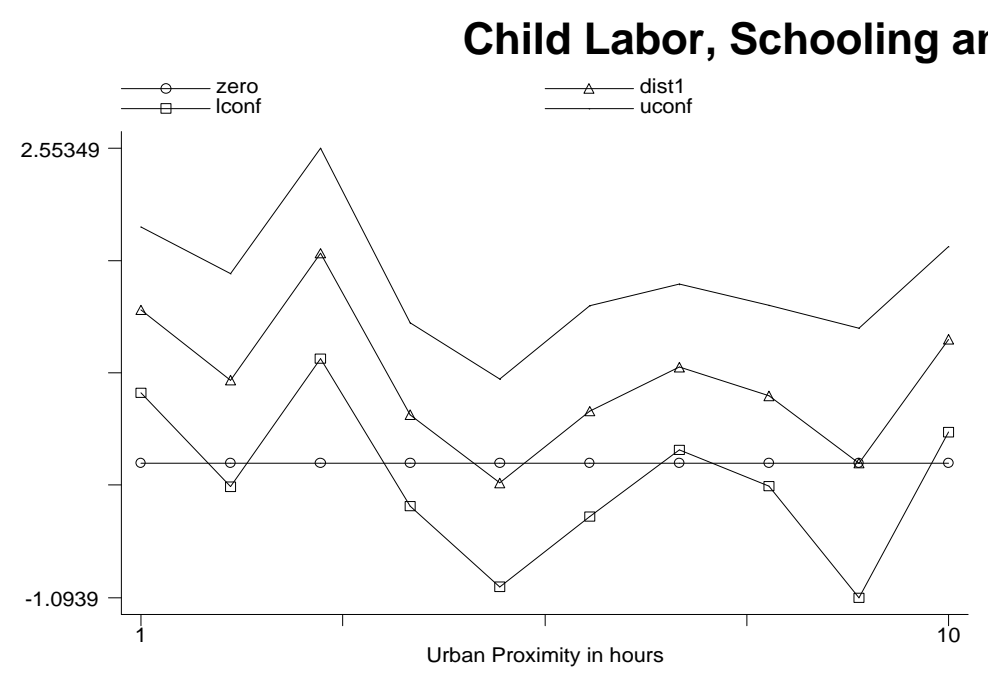

Fig 1.1: Child market work

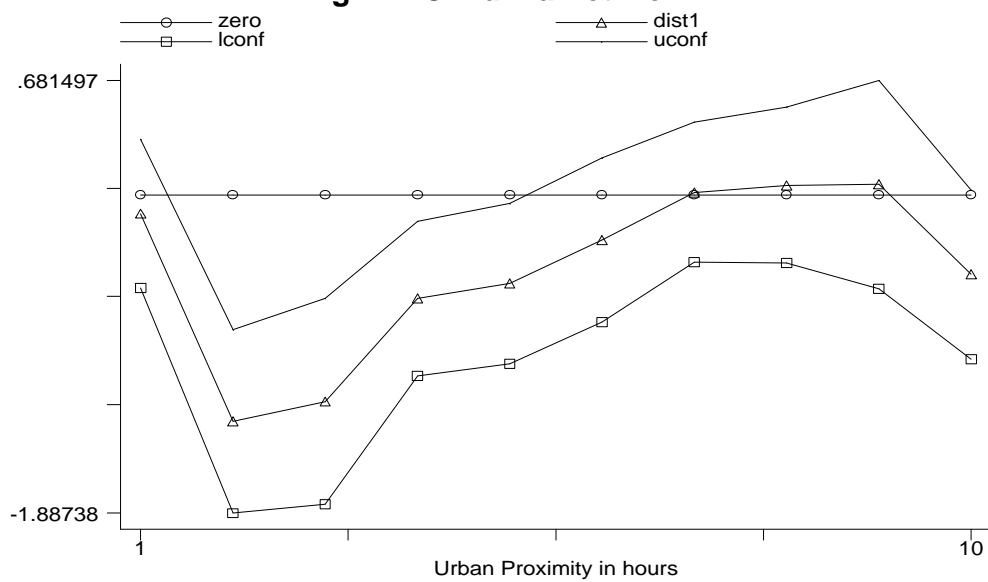

Fig 1.3: Child work in household chores

Key: Each figure plots the reduced form logit coefficients of the urban population variables by hour of travel distance from ward.

The coefficients are shown as the dist1 broken line, together with their 95\% confidence interval (the uconf and lconf broken lines).

Market work refers to wage employment and business self-employment. Subsistence work combines farming, livestock, and crafts.

Fig 1.4: Shool attendance

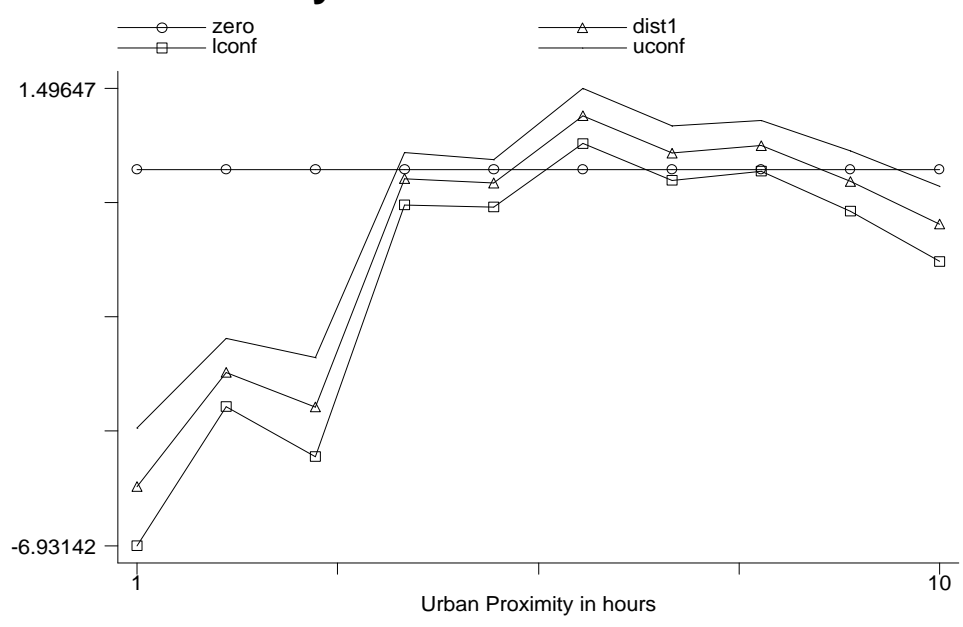

Fig 1.2: Child subsistence work

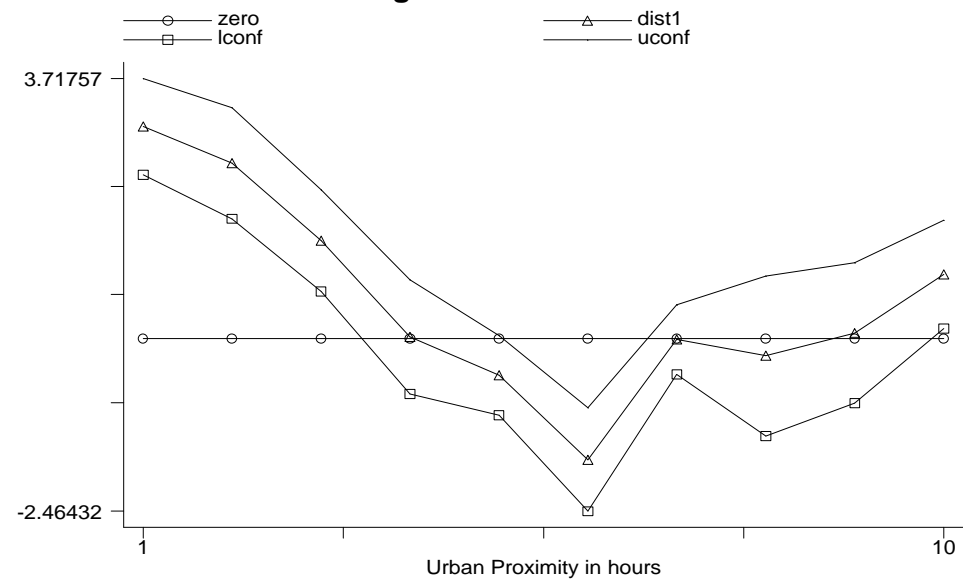




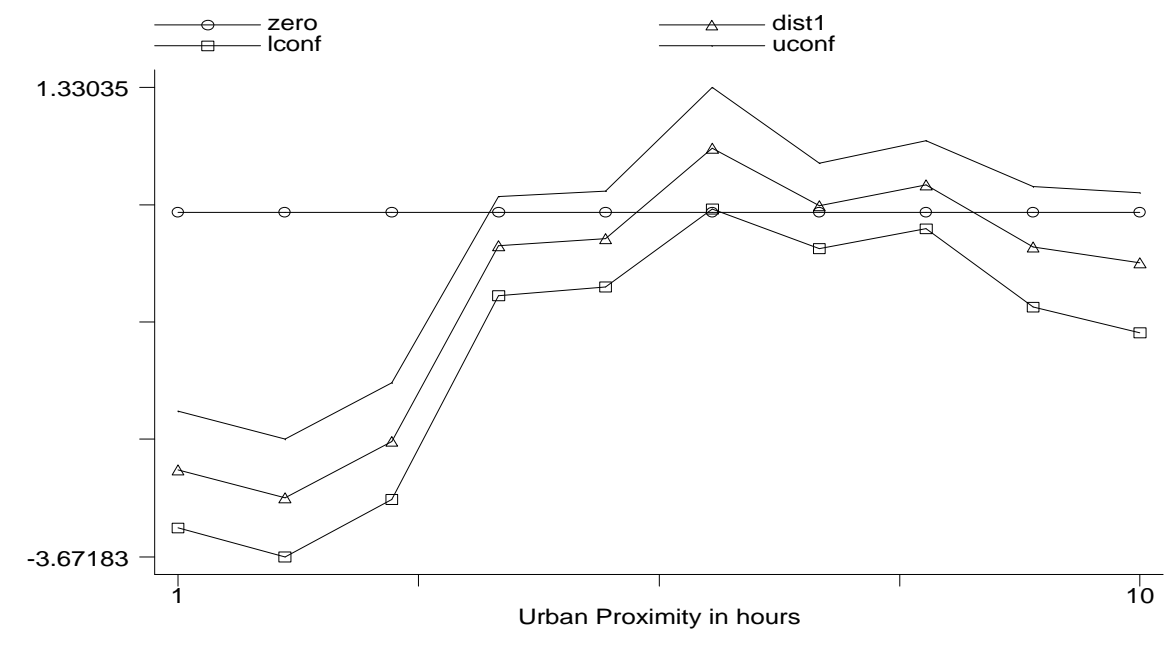

Fig 1.5: Combined market and subsistence work

Key: The figure plots the reduced form logit coefficients of the urban population variables by hour of travel distance from ward.

The coefficients are shown as the dist1 broken line, together with their $95 \%$ confidence interval (the uconf and Iconf broken lines).

Market work refers to wage employment and business self-employment. Subsistence work combines farming, livestock, and crafts.

Here the dependent variable is 1 if the child is engaged in either market or subsistence work, 0 otherwise. 